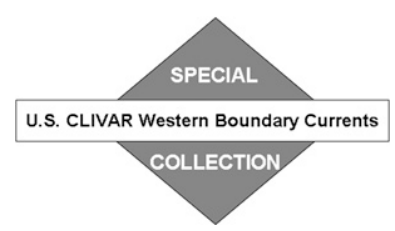

\title{
Role of the Gulf Stream and Kuroshio-Oyashio Systems in Large-Scale Atmosphere-Ocean Interaction: A Review
}

\author{
Young-Oh Kwon,* Michael A. Alexander, ${ }^{+}$Nicholas A. Bond, ${ }^{*}$ Claude Frankignoul, $@$ \\ HISASHI NAKAMURA, \& Bo QIU, $* *$ AND LUANNE THOMPSON ${ }^{++}$ \\ * WHOI, Woods Hole, Massachusetts \\ + NOAA/ESRL, Boulder, Colorado \\ \# JISAO, University of Washington, Seattle, Washington \\ @ LOCEAN/IPSL, Université Pierre et Marie Curie, Paris, France \\ $\&$ Department of Earth and Planetary Science, University of Tokyo, Tokyo, and \\ RIGC/JAMSTEC, Yokohama, Japan \\ ** University of Hawaii at Manoa, Honolulu, Hawaii \\ ++ University of Washington, Seattle, Washington
}

(Manuscript received 13 July 2009, in final form 8 January 2010)

\begin{abstract}
Ocean-atmosphere interaction over the Northern Hemisphere western boundary current (WBC) regions (i.e., the Gulf Stream, Kuroshio, Oyashio, and their extensions) is reviewed with an emphasis on their role in basin-scale climate variability. SST anomalies exhibit considerable variance on interannual to decadal time scales in these regions. Low-frequency SST variability is primarily driven by basin-scale wind stress curl variability via the oceanic Rossby wave adjustment of the gyre-scale circulation that modulates the latitude and strength of the WBC-related oceanic fronts. Rectification of the variability by mesoscale eddies, reemergence of the anomalies from the preceding winter, and tropical remote forcing also play important roles in driving and maintaining the low-frequency variability in these regions. In the Gulf Stream region, interaction with the deep western boundary current also likely influences the low-frequency variability. Surface heat fluxes damp the low-frequency SST anomalies over the WBC regions; thus, heat fluxes originate with heat anomalies in the ocean and have the potential to drive the overlying atmospheric circulation. While recent observational studies demonstrate a local atmospheric boundary layer response to WBC changes, the latter's influence on the large-scale atmospheric circulation is still unclear. Nevertheless, heat and moisture fluxes from the WBCs into the atmosphere influence the mean state of the atmospheric circulation, including anchoring the latitude of the storm tracks to the WBCs. Furthermore, many climate models suggest that the large-scale atmospheric response to SST anomalies driven by ocean dynamics in WBC regions can be important in generating decadal climate variability. As a step toward bridging climate model results and observations, the degree of realism of the WBC in current climate model simulations is assessed. Finally, outstanding issues concerning oceanatmosphere interaction in WBC regions and its impact on climate variability are discussed.
\end{abstract}

\section{Introduction}

Atmosphere-ocean interactions are exceptionally strong over western boundary currents and their eastward extensions (hereafter collectively WBCs): for example, the largest mean and variance at interannual and longer time scales of the net surface heat flux $\left(\mathrm{Q}_{\text {net }}\right)$ over the global ocean occurs in WBC regions (Wallace and Hobbs

Corresponding author address: Dr. Young-Oh Kwon, Physical Oceanography Department, Woods Hole Oceanographic Institution, MS\#21, Woods Hole, MA 02543.

E-mail: yokwon@whoi.edu
2006). Poleward heat transports by the ocean and atmosphere are comparable in the tropics, until the ocean transfers $\sim 70 \%$ of its heat transport to the atmosphere between $25^{\circ}$ and $45^{\circ} \mathrm{N}$. This heat transfer, mainly via latent and sensible energy fluxes during winter, is concentrated near the WBC in each basin [i.e., the Kuroshio in the North Pacific and the Gulf Stream (GS) in the North Atlantic], indicating that these oceanographic features play a key role in the climate system. Strong ocean-toatmosphere fluxes of heat and moisture influence the mean climate by maintaining the surface baroclinicity and energizing storms, anchoring the major storm tracks along the WBCs (Nakamura et al. 2004). 
In this review paper, we examine the role of oceanatmosphere interaction in the vicinity of Northern Hemisphere WBCs in basinwide extratropical climate variability. The companion paper by Kelly et al. (2010) examines atmosphere-ocean interaction over the Gulf Stream and Kuroshio systems primarily from satellite measurements and observations collected during the Kuroshio Extension System Study (KESS; http://uskess.org/) and the Climate Variability and Predictability (CLIVAR) Mode Water Dynamic Experiment (CLIMODE; http://www.climode. org/) field programs. In addition, a comprehensive set of diagnostics - mean, standard deviations, leading empirical orthogonal functions (EOFs), etc.- of various variables in these two WBCs is available online (http://www. cdc.noaa.gov/WBC/).

The leading modes of extratropical atmospheric variability, specifically the Pacific-North America (PNA) teleconnection (Wallace and Gutzler 1981) and the North Atlantic Oscillation (NAO; van Loon and Rogers 1978), include variability on time scales longer than a few years. It has long been hypothesized that the midlatitude oceans influence the low-frequency variability of these patterns, as postulated by Bjerknes (1969), given the ocean's large thermal inertia and relatively slow dynamics. Nevertheless, a consensus is lacking on the significance of the extratropical ocean and ocean-atmosphere interaction in climate variability. At least to first order, observations indicate that the atmosphere forces the ocean, and experiments using atmospheric general circulation models (AGCMs) with specified extratropical sea surface temperature anomalies (SSTAs) generally yield atmospheric anomalies of modest amplitude and variable spatial structure (Kushnir et al. 2002). Given the low-frequency response of WBCs to integrated basinwide atmospheric forcing, the large ocean-to-atmosphere heat fluxes over the WBCs, their proximity to the storm tracks, and the long time scale inherent in the ocean, it is important to determine whether the WBCs have a significant influence on the large-scale atmospheric circulation.

Oceanic changes are primarily communicated to the atmosphere via fluctuations in SST. Processes that determine SST in WBCs include surface heat fluxes (Cayan 1992), Ekman transport acting on the strong SST fronts (Xue et al. 1995), eddies (Qiu 2000), and seasonal variability of upper-ocean mixing leading to the reemergence of SSTAs (Alexander and Deser 1995). Westwardpropagating Rossby waves driven by basin-scale wind stress curl $(\nabla \times \boldsymbol{\tau})$ anomalies (Frankignoul et al. 1997) can initiate changes in ocean circulation in WBCs that lead to meridional displacement of the front (Nakamura and Kazmin 2003) and geostrophic advection changes (Dong and Kelly 2004). In addition, atmospheric teleconnections from the tropics can influence the surface heat flux and Ekman transports in WBCs (Alexander et al. 2002). These processes are schematically summarized in Fig. 1.

In several coupled climate models, ocean-atmosphere interactions in WBCs play a key role in the existence of the extratropical decadal variability (Pierce et al. 2001; Wu and Liu 2005; Kwon and Deser 2007). These models reproduce many features of the observed decadal variability, including upward surface heat fluxes associated with anomalously warm SSTs in WBCs that heat the overlying atmosphere. The mechanisms diagnosed using coupled climate models depend on the atmospheric response to WBC SSTAs, which is still uncertain. Most of the current coupled climate models have coarse resolution, particularly in the ocean, with many biases; therefore, a detailed assessment of these models is critical for evaluating mechanisms for WBC-related variability.

In addition to the atmospheric response to WBC SSTAs, other outstanding issues considered here include 1) the connection between frontal-scale boundary layer oceanatmosphere interaction and the basin-scale variability, 2) potential changes in WBC ocean-atmosphere interaction due to global warming, 3 ) the relationship between the meridional overturning circulation (MOC) and the GS variability in the North Atlantic, and 4) interbasin connection between the Kuroshio-Oyashio Extension (KOE) and GS variability.

The rest of the paper is organized as follows. Section 2 describes processes that influence WBC SST variability. Section 3 discusses the importance of WBCs in basinscale climate variability as indicated by observations and climate models. Section 4 discusses WBC-related metrics for assessment of the performance of the current generation of climate models. Section 5 examines outstanding questions related to the role of WBCs in the basin-scale climate variability. A brief summary is provided in section 6 .

\section{Processes affecting the SST variability in the WBCs}

\section{a. Shift of oceanic fronts}

Extratropical SST variability is large near regions of strong SST gradients along oceanic fronts associated with WBCs (Fig. 2; Nakamura et al. 1997; Nakamura and Yamagata 1999; Frankignoul et al. 2001; Nakamura and Kazmin 2003). Decadal SST variability is particularly strong along the subarctic (or subpolar) frontal zones (SAFZs) in the KOE region of the North Pacific and along the GS in North Atlantic. These frontal zones correspond to the boundaries between the subtropical and subpolar gyres where displacement of the frontal 


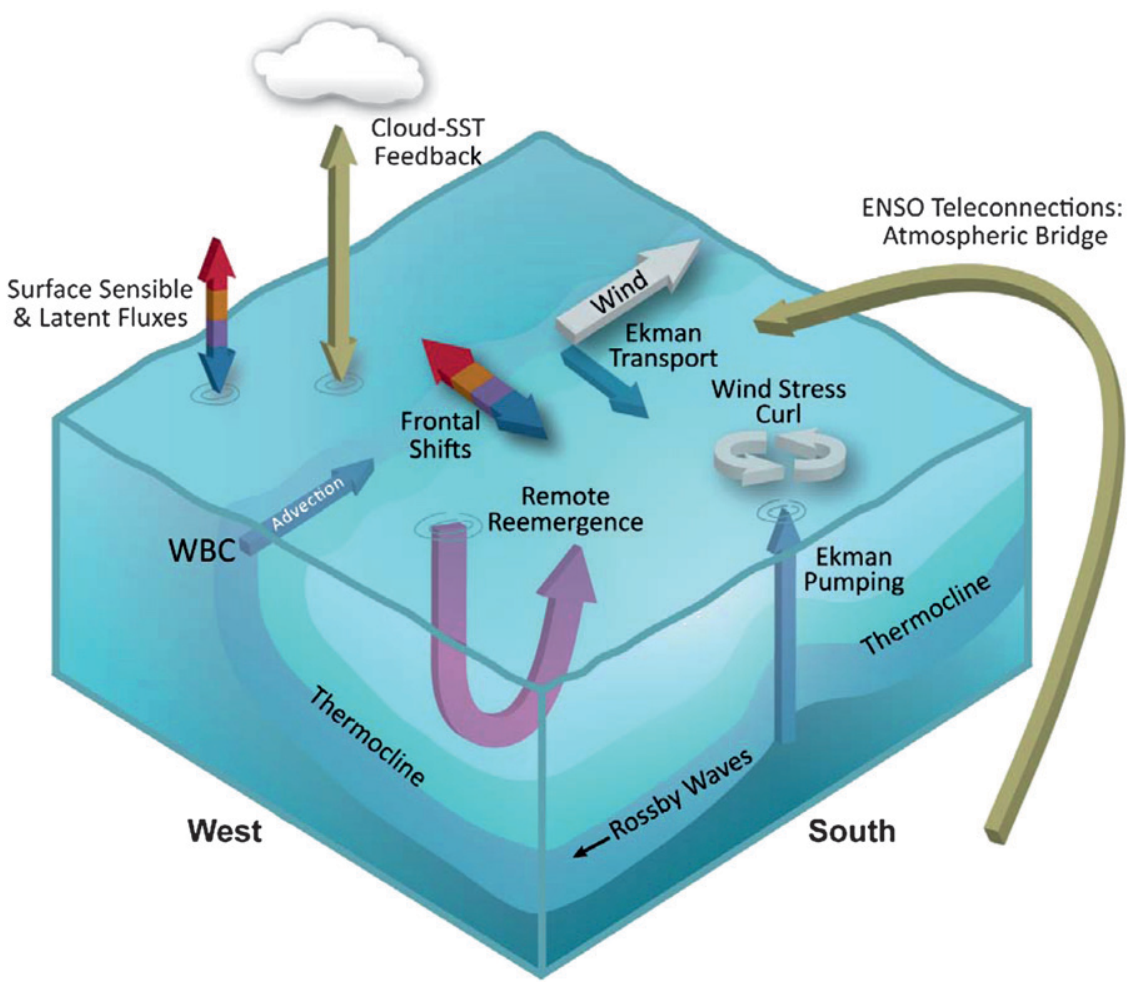

FIG. 1. Schematic summary of the processes affecting the SST variability in the WBC region.

axis generates strong SSTAs (Seager et al. 2001; Joyce et al. 2009).

The axial displacement of the gyre boundaries on a multiyear time scale is most evident when averaged over its longitudinal extent. As observed by Nakamura and Kazmin (2003), the axis of the North Pacific SAFZ was displaced from $42.5^{\circ} \mathrm{N}$ around 1970 to $40.5^{\circ} \mathrm{N}$ in the mid-1980s, yielding a $\sim 2^{\circ} \mathrm{C}$ SST decline. Compared to the North Atlantic, where a single SST front is located between the GS and Labrador Current, the North Pacific SAFZ is more variable and has a more complicated structure, with two oceanic fronts along the Kuroshio and
Oyashio Extensions (KE and OE, respectively) and a mixed water region in between (Yasuda et al. 1996; Yuan and Talley 1996; Belkin et al. 2002; Yasuda 2003). Resolution of conventional gridded temperature data is not quite sufficient for distinguishing the two fronts. A 50-yr hindcast integration using an eddy-resolving OGCM [the OGCM for the Earth Simulator (OFES)] with observed daily atmospheric forcing (Masumoto et al. 2004; Ohfuchi et al. 2007) reveals distinctive characteristics of temperature variability associated with the KE and $\mathrm{OE}$ fronts that arise from differences in their vertical structure (Nonaka et al. 2006). The OE front, located at $\sim 41^{\circ} \mathrm{N}$,

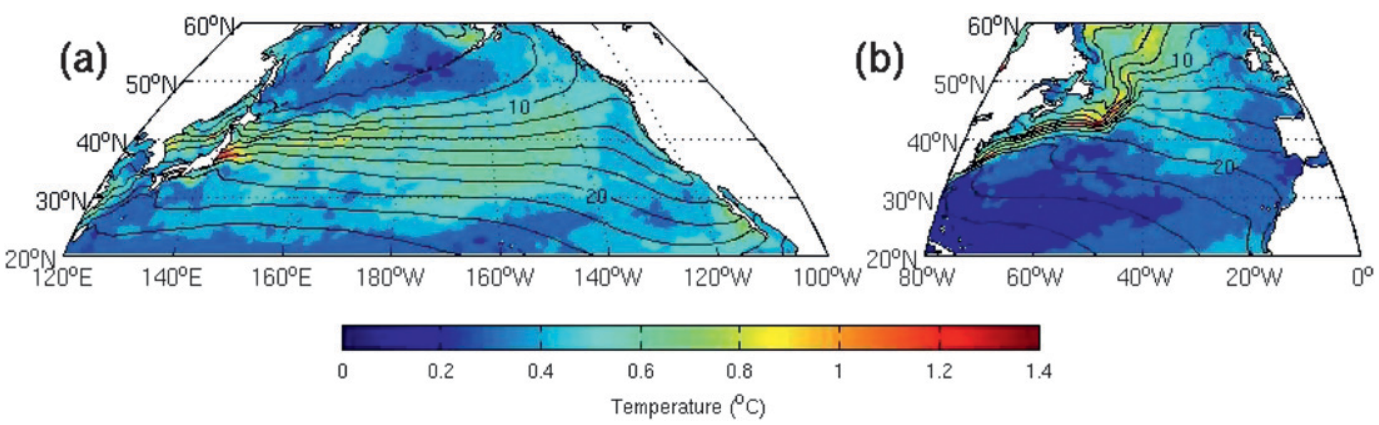

FIG. 2. Climatological mean (contours) and standard deviation (color shading) of the annual mean SST for 19822008 based on the NOAA high-resolution $\left(0.25^{\circ}\right.$ latitude $\times 0.25^{\circ}$ longitude) SST dataset version 2 (Reynolds et al. 2007). The contour intervals (CIs) for the mean are $2^{\circ} \mathrm{C}$ : (a) North Pacific and (b) North Atlantic. 

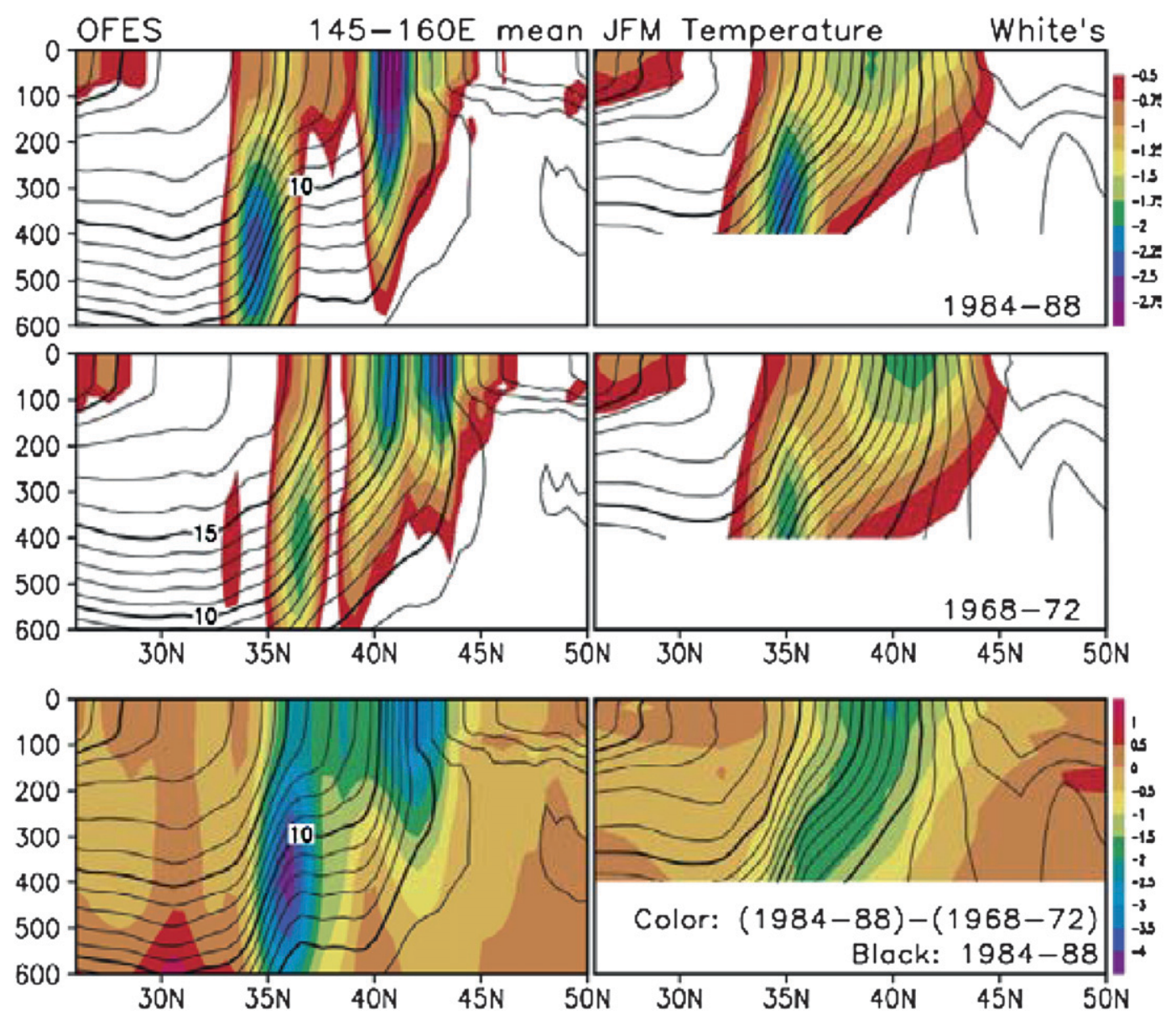

FIG. 3. Latitude-depth sections for five-winter (January-March) mean fields of temperature (black contours) and meridional gradient (color shading; top right) for (top) 1984-88 and (middle) 1968-72, based on their averages between $145^{\circ}$ and $160^{\circ} \mathrm{E}$ for (left) the OFES simulation and (right) hydrographic observations compiled by White (1995). (bottom) Color shadings (bottom right) indicate the changes in five-winter mean temperature from 1968-72 to $1984-88$. CIs for temperature are $1^{\circ} \mathrm{C}$. Unit for the gradients is ${ }^{\circ} \mathrm{C}(100 \mathrm{~km})^{-1}$. [After Nonaka et al. (2006).]

is strongest at the surface, whereas the KE front, located at $\sim 35^{\circ} \mathrm{N}$, is strongest between 200 and $600 \mathrm{~m}$ below the surface (Fig. 3). When displaced meridionally, the OE and $\mathrm{KE}$ fronts create strong thermal anomalies mainly in the mixed layer (ML) and at the thermocline level, respectively. Given its deep structure, the KE front is strongly influenced by large-scale changes in the subtropical gyre driven by wind stress changes across the North Pacific (Qiu 2000, 2003; Qiu and Chen 2005; Taguchi et al. 2005; Nonaka et al. 2006), as discussed in section $2 \mathrm{f}$.

The KE and OE fronts both underwent southward displacement and intensification in the mid-1980s, as shown with the OFES hindcast integration. However, the southward shift happened slightly earlier for the OE front, indicating that their axial migration may not be synchronized. In the OFES hindcast integration, the intensity and latitude of the OE front are closely related to the strength of the Oyashio, which tends to be strongly influenced by the wind forcing exerted on the western portion of the subpolar gyre but not on the central or eastern portion (Nonaka et al. 2008). The SAFZs are also characterized by meridional salinity gradients with less saline water to their north, and thus their axial displacement yields salinity anomalies that are collocated with SSTAs.

Similarly, the GS axis has undergone large meridional excursions, and since the early 1990s it has been found 100 to $200 \mathrm{~km}$ farther north than during the 1960s (Joyce et al. 2000). The GS shifts are influenced by changes in the NAO; that is, the GS moves north during positive phases of the NAO (Taylor and Stephens 1998; Joyce et al. 2000; Frankignoul et al. 2001). The GS shifts are also influenced by the variability of the deep western boundary current (DWBC) in the Slope Water region; that is, larger DWBC transport leads to southward shift 
of the GS (Dong and Kelly 2003; Peña-Molino and Joyce 2008).

\section{b. Oceanic advection}

Unlike in central and eastern portions of the North Atlantic and Pacific basins where the horizontal temperature gradients and currents are generally weak, variability in the heat content of the upper ocean (i.e., from the surface to the thermocline level) in the WBCs on interannual and longer time scales is determined mainly by anomalous geostrophic advection, which tends to dominate over the Ekman advection and $Q_{\text {net }}$ (Qiu and Kelly 1993; Qiu 2000; Tomita et al. 2002; Dong and Kelly 2004; Kelly and Dong 2004). Anomalous geostrophic currents associated with changes in both the axial position and intensity of the gyre boundaries yield anomalous thermal advection in WBCs. For example, ML heat budgets computed by Qiu (2000) and Vivier et al. (2002) suggest that anomalous geostrophic heat advection due mainly to anomalous currents, as opposed to the mean advection of temperature anomalies, contributes primarily to SST tendencies observed in the transitions between the elongated and contracted stages of the KE. In these analyses, surface geostrophic velocity was derived from satellite-measured sea surface height (SSH) fields, whereas Ekman velocity was derived from atmospheric reanalysis data. See Kelly et al. (2010) for a detailed discussion of the heat budget in WBCs.

Furthermore, the OFES hindcast integration suggests that the intensification of the Oyashio and the southward displacement of its extension generated negative SSTAs along the OE front in the mid-1980s (Nonaka et al. 2006, 2008). During the same period, cooling along the KE front was caused by the southward shift of the KE current rather than its intensification (Deser et al. 1999). As pointed out by Tomita et al. (2002), anomalous thermal advection, including the effect of the mean current, below the ML bottom in summer cannot be neglected, since it can contribute to the formation of subsurface thermal anomalies that could be entrained into the ML in following fall and winter (Xie et al. 2000; see section 2e).

\section{c. Surface heat fluxes}

The quantity $Q_{\text {net }}$ in the WBCs undergoes a substantial seasonal cycle with respect to its sign and dominant component (e.g., Kubota et al. 2002). Upward $Q_{\text {net }}$ is strongest in winter and is dominated by latent heat flux along the KE and GS. Upward sensible heat flux is also significant in winter, especially over the marginal seas off the Asian continent. The heat flux is enhanced by episodic outbreaks of cold, dry air of continental origin (Xue et al. 1995; Ninomiya 2006). The presence of oceanic fronts yields tight cross-frontal gradients in the sensible and latent heat fluxes (Fig. 4; Taguchi et al. 2009; Kelly et al. 2010). During the cold season, the local heat fluxes in the WBCs are strongly dependent on wind direction and thus highly variable in time because of the frequent passage of atmospheric disturbances (Taguchi et al. 2009). The cross-frontal contrast in the surface fluxes can efficiently restore the surface air temperature gradient against the relaxing effect of atmospheric disturbances (Nonaka et al. 2009), which is thus important for the formation of storm tracks and the attendant polar-front jet streams (Nakamura et al. 2004, 2008; Sampe et al. 2010). This restoration is possible because of the large thermal inertia of the deep ocean ML and the maintenance of the fronts by oceanic advection. The large heat and moisture fluxes to the south of the WBCs can enhance latent heating associated with cyclones, thereby acting to organize precipitation bands and the associated heat source regions for atmospheric planetary waves (Hoskins and Valdes 1990; Minobe et al. 2008).

Over most of the midlatitude oceans $Q_{\text {net }}$ variability is controlled largely by the atmosphere (Cayan 1992; Frankignoul and Kestenare 2002), as indicated by a negative local correlation observed between SST and turbulent heat flux (positive upward) anomalies. On the other hand, ocean heat content and SSTAs become more important in determining the heat flux anomalies in WBCs with positive local SST-surface flux correlations (Frankignoul and Kestenare 2002; Tanimoto et al. 2003; Park et al. 2005). The upper-ocean heat content in the WBCs is determined by both the ocean dynamics and integrated heat fluxes [Vivier et al. (2002) for the Pacific; Dong and Kelly (2004) for the Atlantic]: the former dominates at low frequencies, whereas the latter is important for shorter-term variability. Indeed, intermonthly to interannual fluctuations in the intensity of the winter monsoon strongly impact SSTAs over the marginal seas and the KOE region (Fig. 4).

The $Q_{\text {net }}$ is downward in summer when solar radiation dominates. The rate of warming in summer in the vicinity of the KE is influenced by the regional atmospheric circulation's impacts on clouds (Bond and Cronin 2008). Within the subpolar gyre SST remains relatively low even in summer, acting to increase static stability in the planetary boundary layer (PBL). The ocean cools the warm moist air advected from the south, leading to the formation of low-level stratus and fog within the PBL. A particularly sharp transition of this sort occurs on the northern sides of the KE and OE SST fronts (Tokinaga et al. 2009). The prevalence of clouds over the subpolar gyre reduces solar insolation because of the high albedo of low clouds, thereby maintaining low SSTs (Weare 1994; Norris and Leovy 1994; Klein 

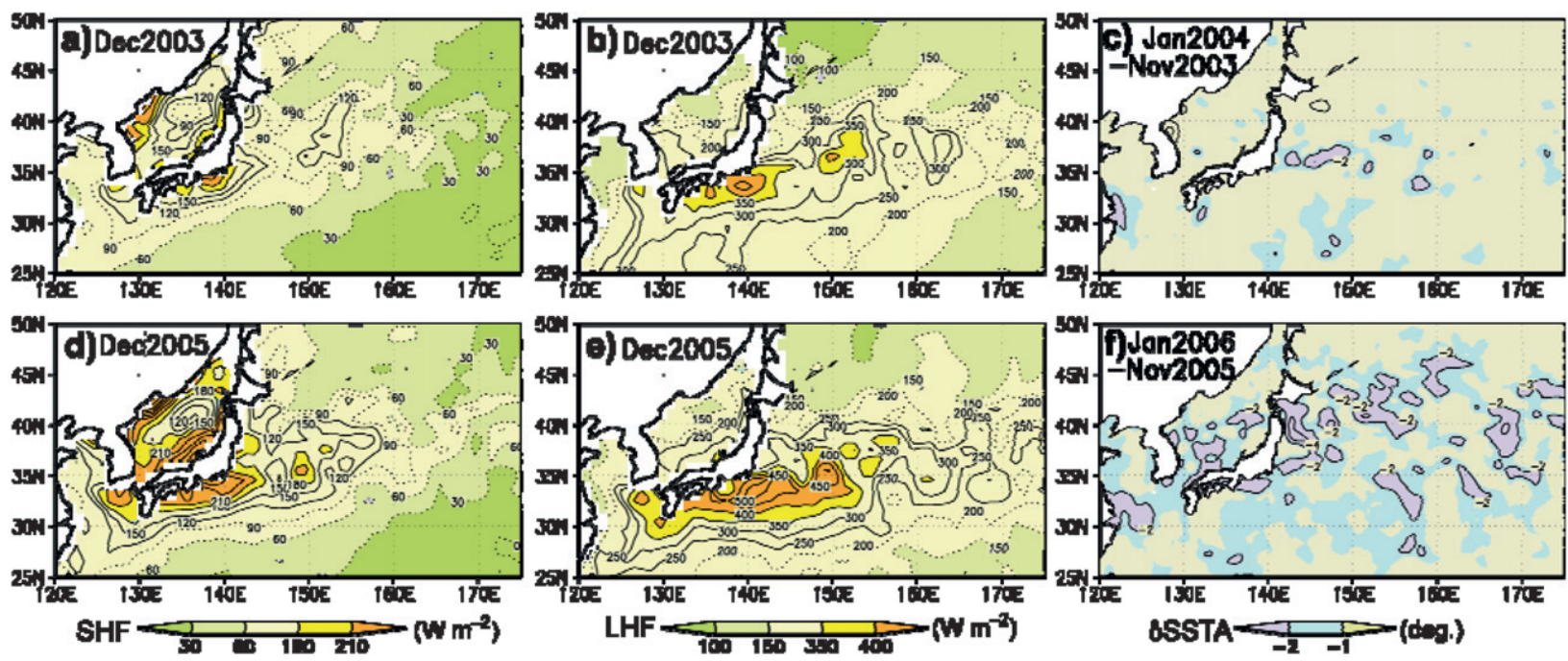

FIG. 4. Monthly $1^{\circ}$ resolution (a),(d) sensible heat flux (SHF; $\mathrm{W} \mathrm{m}^{-2}$ ) and (b),(e) latent heat flux (LHF; $\mathrm{W} \mathrm{m}^{-2}$ ) from the ocean for December (a),(b) 2003 and (d),(e) 2005 over the western North Pacific, shaded as indicated below (d) and (e). CIs are (a), (d) 30 (solid lines for $\geq 120$; dashed lines for $\leq 90$ ) and (b),(e) 50 (solid lines for $\geq 250$; dashed lines for $\leq 200$ ). Figures are based on the Japanese Ocean Flux Datasets with Use of Remote Sensing Observations (JOFURO; Kubota et al. 2002), which have been derived from moisture data from microwave sensor [Defense Meteorological Satellite Program (DMSP)/Special Sensor Microwave Imager (SSM/I)] and SST (Reynolds et al. 2007). ECMWF analysis data have also been incorporated into the estimation of SHF. Note that the East Asian winter monsoon in December was close to the normal strength in 2003, while in 2005 it was the strongest in the postwar period. (c),(f) Anomalous bimonthly SST tendency into January from November of 2003 and 2005, shaded as indicated. Contoured for the strong cooling tendency of $2^{\circ}$ and $4^{\circ}$ C. (From T. Miyasaka 2009, private communication).

et al. 1995). This positive "cloud-SST feedback" can thus enhance and prolong summertime SSTAs near the North Pacific SAFZ (Norris et al. 1998; Park et al. 2006). This feedback also depends on the position of the KE front relative to a quasi-stationary seasonal frontal system in the atmosphere (Baiu front) that separates warm moist subtropical air from cooler and drier air to the north. Fog (stratocumulus) formation is likely when the Baiu front is located to the north (south) of the SST front (Norris and Iacobellis 2005; Tanimoto et al. 2009). The position of the Baiu front is sensitive to atmospheric processes, including the subseasonal intrinsic variability of the atmospheric circulation and interannual variability including the remote influence of El Niño-Southern Oscillation (ENSO; see section 2g). Summertime fog is also common over the relatively cool SSTs of the North Atlantic near the Grand Banks (Taylor 1917; Lewis et al. 2004).

\section{d. Ekman transport}

Ekman transport responds quickly to changes in surface winds and can thus generate SSTAs with the passage of storms (Xue et al. 1995), especially where SST gradients are large. On seasonal and longer time scales, anomalous Ekman transports, induced by changes in the surface westerlies, create SSTAs via meridional advection across the North Pacific SAFZ and the GS-North Atlantic Current (NAC). They can also influence SSTs over a broader region because of the high wind speed fluctuations over the central North Pacific and Atlantic associated with the dominant modes of basinwide atmospheric variability (Seager et al. 2001; Alexander and Scott 2008). For the KOE region, fluctuations in the zonal winds occur in a broad band extending from about $20^{\circ}$ to $50^{\circ} \mathrm{N}$ in association with basin-scale atmospheric anomalies, including the PNA pattern (Nakamura et al. 1997) and the western Pacific (WP) pattern or North Pacific Oscillation (NPO; Linkin and Nigam 2008; Sugimoto and Hanawa 2009). The PNA pattern influences the magnitude of the wind stress over the basin, whereas the WP/ NPO is accompanied by meridional shifts of the wind stress pattern. The zonal wind anomalies associated with the NAO are weak in the immediate vicinity of the GS but of opposite sign to its north and south and therefore tend to modulate the Ekman convergence rather than the overall meridional transports at the GS (Kushnir et al. 2002; Shaffrey and Sutton 2004). Ekman transports tend to reinforce the $Q_{\text {net }}$ in midlatitudes because stronger westerlies cool the ocean by the sensible and latent heat fluxes and by southward Ekman transport (Peng et al. 2006; Alexander and Scott 2008). Furthermore, the crossfrontal cold Ekman advection lowers the near-surface stratification on the warmer side of the front, acting to 

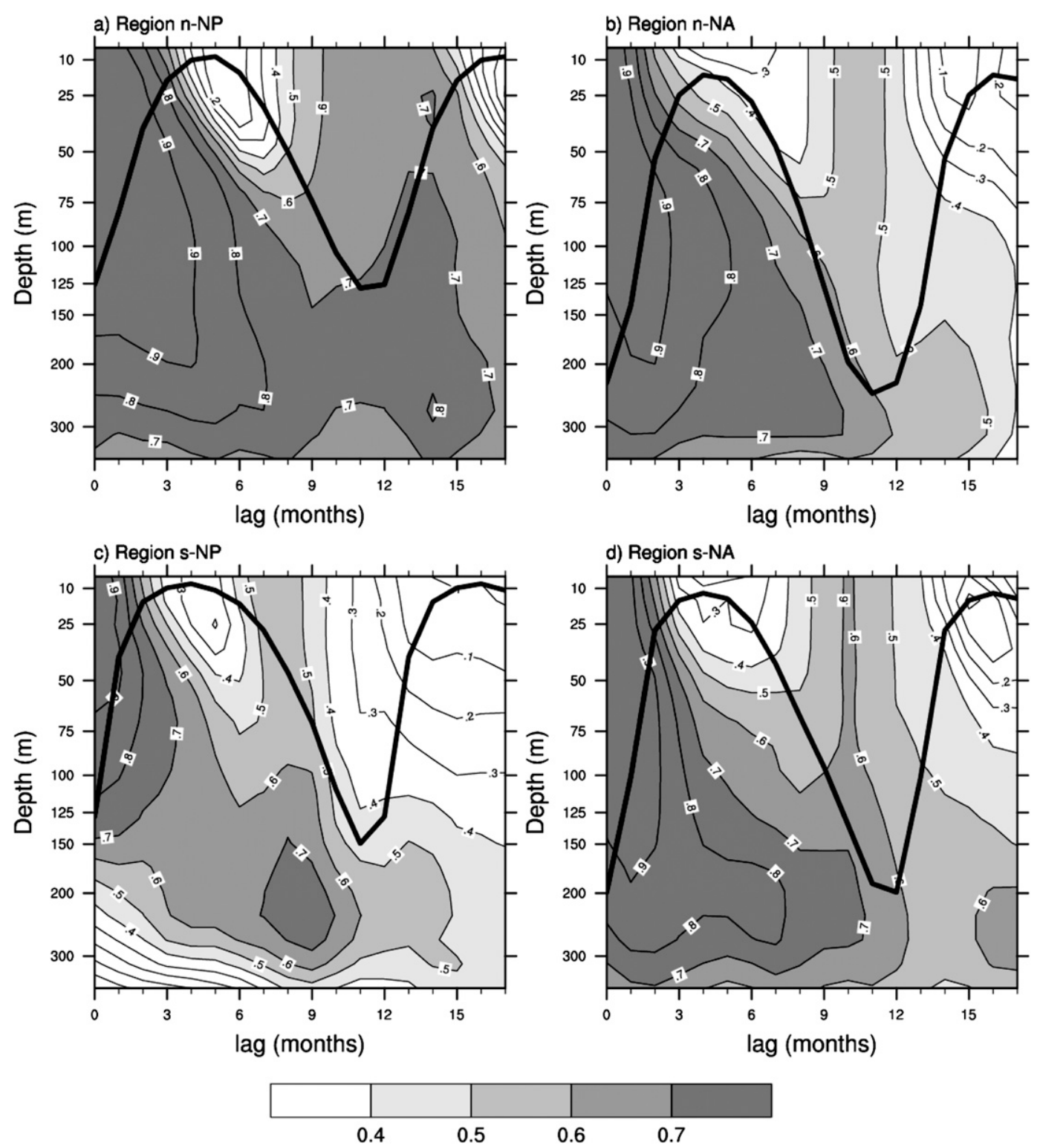

FIG. 5. Distribution of lag correlation coefficients as a function of depth with the reference temperature averaged from the sea surface to 20-m depth during March, the month of deepest MLD, for the (a) northern North Pacific $\left(37^{\circ}-45^{\circ} \mathrm{N}, 157^{\circ} \mathrm{E}-179^{\circ} \mathrm{W}\right)$, (b) northern North Atlantic $\left(41^{\circ}-53^{\circ} \mathrm{N}, 19^{\circ}-35^{\circ} \mathrm{W}\right)$, (c) southern North Pacific $\left(27^{\circ}-33^{\circ} \mathrm{N}\right.$, $\left.141^{\circ}-159^{\circ} \mathrm{E}\right)$ and $(\mathrm{d})$ southern North Atlantic $\left(33^{\circ}-39^{\circ} \mathrm{N}, 45^{\circ}-65^{\circ} \mathrm{W}\right)$. The averaging regions are same as in Hanawa and Sugimoto (2004). The solid line in each panel denotes seasonal change of the MLD. The temperatures are from the Simple Ocean Data Assimilation (SODA; Carton and Giese 2008) for the years 1958-2007 and the long-term mean MLD is from White (1995).

enhance vertical mixing in the ocean (Thomas and Lee 2005).

\section{e. Reemergence mechanism}

The seasonal evolution of ML depth (MLD) and entrainment can result in midlatitude SSTAs recurring from one winter to the next without persisting through the intervening summer (Fig. 5; Namias and Born 1970, 1974).
This process, referred to as the "reemergence mechanism" (Alexander and Deser 1995), occurs when temperature anomalies that form at the surface and spread throughout the deep winter ML remain beneath the ML when it shoals in spring. The thermal anomalies are then incorporated into the summer seasonal thermocline where they are insulated from surface fluxes that damp anomalies in the ML. When the ML deepens again in 
the following fall, the anomalies are re-entrained into the surface layer and influence SST. The reemergence mechanism occurs over large portions of the North Atlantic and North Pacific Oceans, where it explains approximately $15 \%-35 \%$ of the wintertime SST variability (Alexander et al. 1999, 2001; Bhatt et al. 1998; Watanabe and Kimoto 2000; Timlin et al. 2002) including in the KOE and GS regions (de Coëtlogon and Frankignoul 2003; Hanawa and Sugimoto 2004).

The reemergence mechanism described above is fundamentally a local process typical for regions adjacent to the WBCs and in the central and eastern portions of a basin, where ocean currents are relatively weak. Along the WBCs, however, strong advection by the mean currents can transport the anomalies over $\sim 800 \mathrm{~km}$ along the NAC and $\sim 4000 \mathrm{~km}$ along the KE (Fig. 6) over the course of a year (de Coëtlogon and Frankignoul 2003; Sugimoto and Hanawa 2005, 2007). Sugimoto and Hanawa $(2005,2007)$ suggest that the remote reemergence in the KE region is associated with the North Pacific Subtropical Mode Water (STMW) and Central Mode Water (CMW) [see Kelly et al. (2010) for detailed discussion of the mode waters]. In WBCs, the reemergence mechanism can also bring thermal anomalies created at depth by dynamical ocean processes to the surface during winter (Xie et al. 2000; Vivier et al. 2002; Tomita et al. 2002). Anomalous geostrophic heat advection and/or the axial migration of the WBCs and associated frontal zones can yield subsurface temperature anomalies that persist over multiple years (Fig. 3), which can be entrained into the ML in fall and winter (Nonaka et al. 2006). In summer, the shallow ML shields the subsurface water from thermal damping by $Q_{\text {net }}$. As a result, summertime decadal SSTAs in the KOE region are not coherent with subsurface temperature anomalies, as indicated by an eddy-resolving OGCM integration (Nonaka et al. 2006), and decadal SST variability observed east of Japan (140 ${ }^{\circ}$ $\left.150^{\circ} \mathrm{E}\right)$ is significantly weaker in summer than in winter (Nakamura and Yamagata 1999).

\section{f. Remote wind stress curl forcing communicated via oceanic Rossby waves}

Variability in the WBCs is not only generated by local processes; it also arises from remote forcing that is conveyed to the $\mathrm{KOE}$ and GS regions via the ocean and atmosphere. Remote forcings of WBC fluctuations include wind-driven extratropical Rossby waves and atmospheric teleconnections emanating from tropical ocean basins. Anomalies advected by the ocean from high latitudes and changes in the Atlantic MOC also impact the GS, as discussed in sections $3 b$ of Kelly et al. (2010) and 5d of this paper.

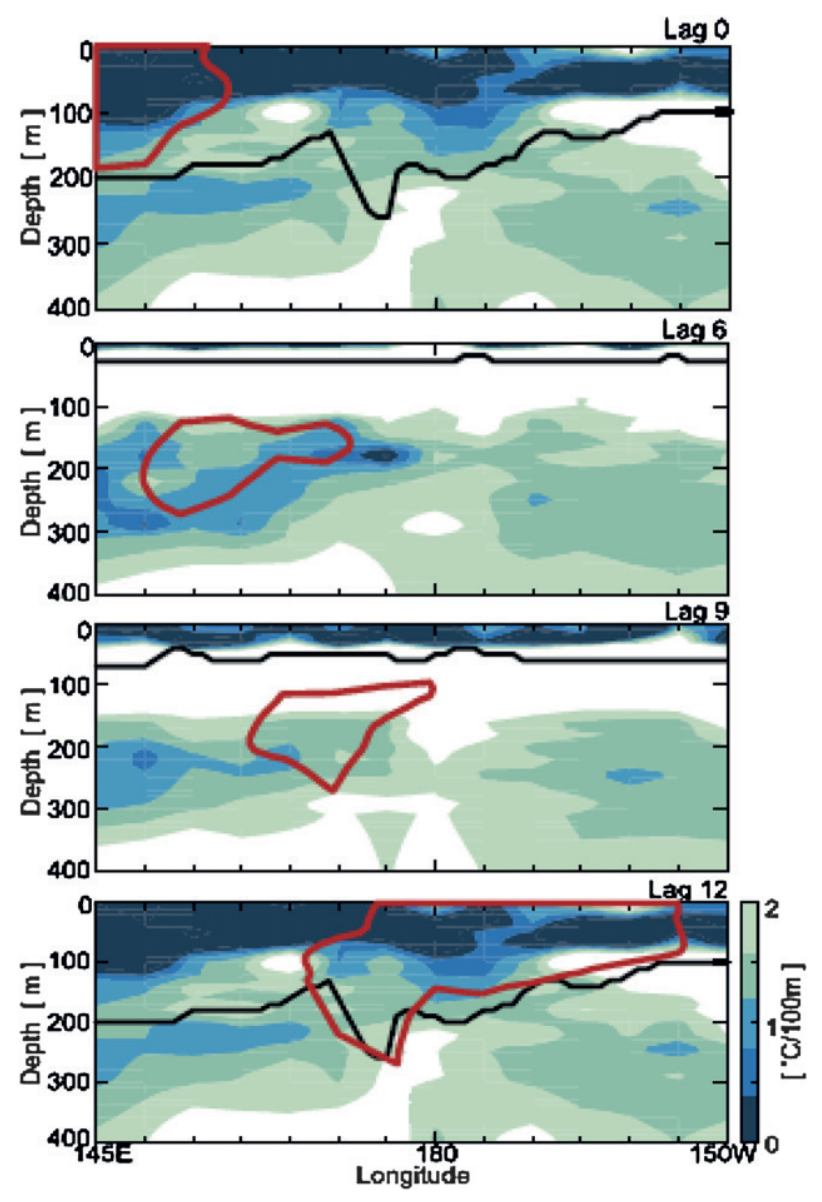

FIG. 6. Vertical sections showing reemergence of SST anomalies over the North Pacific along the line between $30^{\circ} \mathrm{N}, 145^{\circ} \mathrm{E}$ and $34^{\circ} \mathrm{N}, 150^{\circ} \mathrm{W}$. Red lines indicate domains where the correlation coefficients of subsurface temperature anomalies with a reference index exceed 0.7 for lags of (top to bottom) $0,6,9$, and 12 months. The index has been defined as winter-mean SST anomalies averaged over $27^{\circ}-33^{\circ} \mathrm{N}, 137^{\circ}-154^{\circ} \mathrm{E}$. Color shading represents the strength of vertical temperature gradient $\left[{ }^{\circ} \mathrm{C}(100 \mathrm{~m})^{-1}\right]$, as indicated on the right. Black lines denote the mixed layer bottom. (After Sugimoto and Hanawa 2005.)

The dynamic adjustment of upper-ocean gyre circulations primarily occurs through westward-propagating, first-baroclinic-mode Rossby waves, which exhibit quasinon-Doppler shift propagation (Liu 1999a) and are forced by anomalous $\boldsymbol{\nabla} \times \boldsymbol{\tau}$ (Frankignoul et al. 1997; Miller et al. 1998; Deser et al. 1999; Schneider et al. 2002; Qiu and Chen 2005; Taguchi et al. 2007). (Note that the higher baroclinic mode can also be forced by local buoyancy forcing in the WBCs where mode water is formed; Liu 1999a,b; Thompson and Ladd 2004). This mechanism is illustrated by Hovmöller diagrams of SSH anomalies for a zonal band in the North Pacific based on altimetry data (Fig. 7a) and a baroclinic Rossby wave model (Fig. 7b), with a time series of the leading mode of SST variability, 


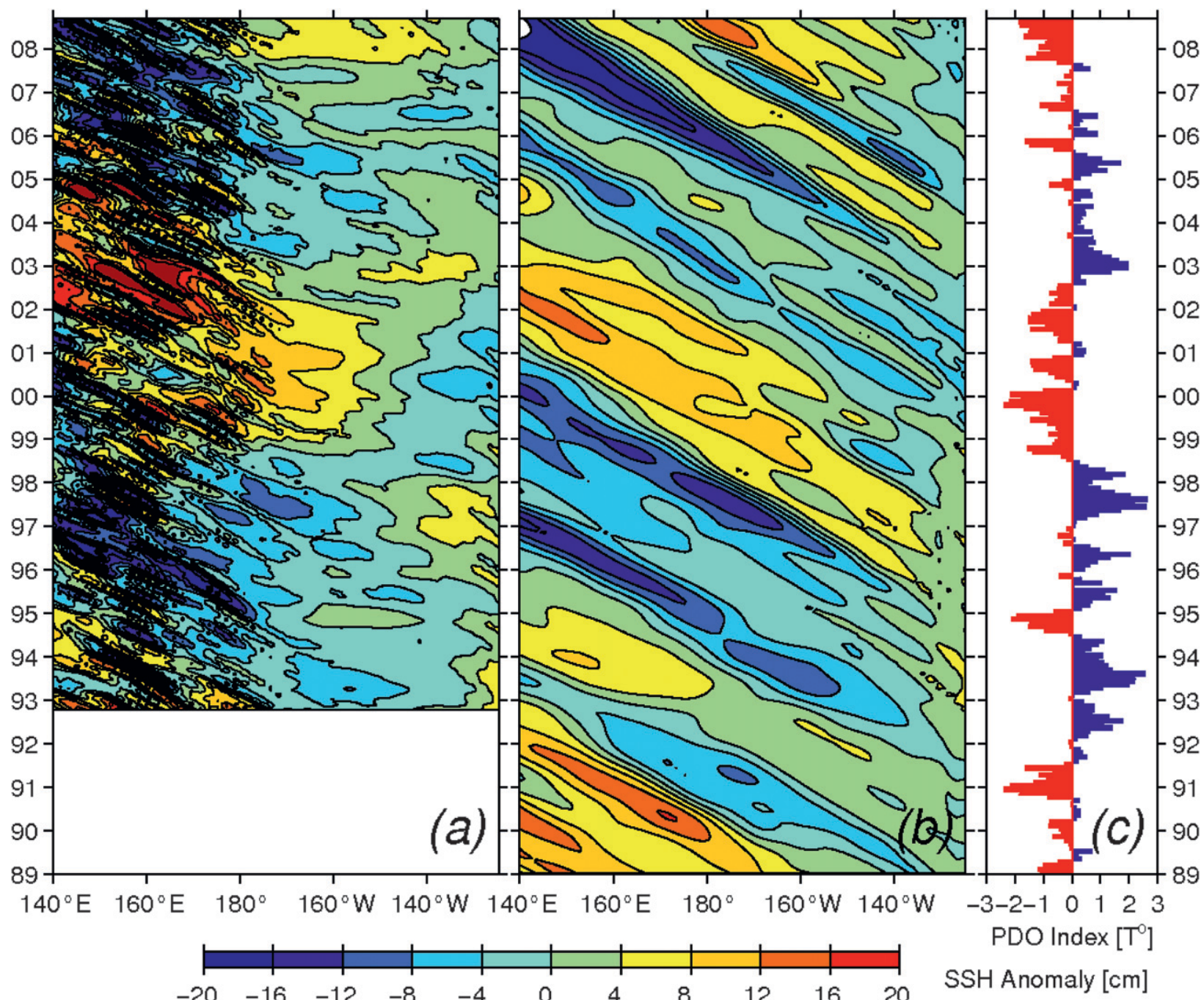

FIG. 7. SSH anomalies along the zonal band of $32^{\circ}-34^{\circ} \mathrm{N}$ in the North Pacific from (a) satellite altimeter data and (b) the wind-forced baroclinic Rossby wave model, where the winds are obtained from the NCEP-NCAR reanalysis (Kistler et al. 2001). (c) PDO SST index as defined by Mantua et al. (1997; available online at http://jisao.washington.edu/pdo/PDO.latest).

the Pacific decadal oscillation (PDO; Mantua et al. 1997), linked to the wind forcing (Fig. 7c). When the Aleutian low intensifies and shifts southward (i.e., the positive phase of the PDO), it cools the central North Pacific and generates negative SSH anomalies in the eastern North Pacific through Ekman divergence. Once generated, the $\mathrm{SSH}$ anomalies propagate westward at $\sim 3.8 \mathrm{~cm} \mathrm{~s}^{-1}$, slightly faster than the theoretical value for the first long baroclinic Rossby wave at corresponding latitudes in the absence of mean flow (Chelton and Schlax 1996). The altimetry data include the effects of small-scale eddy variability that is not represented by the Rossby wave model. Nevertheless, the correlation between the observed and simulated SSH anomaly fields is 0.45 for monthly values and 0.53 when only interannual and longer SSH signals are retained. Oceanic Rossby waves excited by the meridional SLP dipole associated with the NPO, the second leading mode of SLP variability over the Pacific, were also recently shown to influence KE variability (Ceballos et al. 2009). The arrival of Rossby waves not only alters the KE intensity but also modulates eddy activity (Fig. 7a; Qiu and Chen 2005; Taguchi et al. 2005, 2007; Dawe and Thompson 2007).

The first baroclinic-mode Rossby wave adjustment process, primarily through horizontal displacement of the WBC front and vertical displacement of the thermocline, appears to explain much of the observed lowfrequency variability of SST, thermocline, and SSH near the KOE (Schneider and Miller 2001; Qiu 2003; Taguchi et al. 2007) and GS (Frankignoul et al. 1997; Sturges 
et al. 1998; Sirven et al. 2002). Although wind-driven baroclinic Rossby waves are also apparent from satellite data in the North Atlantic (Fig. 8; Osychny and Cornillon 2004), their impact on the GS variability is less clear than in the Pacific (see section 3b of Kelly et al. 2010). The limited impact of Rossby waves on the GS may be due to several factors, including the facts that (i) the basin is relatively small (i.e., the $\boldsymbol{\nabla} \times \boldsymbol{\tau}$ forcing occurs close to the GS); (ii) the GS is meridionally slanted and the incoming Rossby wave signals in the GS from different latitudes can have different phases, resulting in SSH anomalies less likely to be organized; and (iii) lowfrequency GS fluctuations are also influenced by fluctuations in the strength of the northern recirculation gyre and by the Atlantic MOC.

\section{g. Tropical atmospheric teleconnections}

ENSO-driven atmospheric teleconnections [see reviews by Trenberth et al. (1998) and Liu and Alexander (2007)] alter the surface fluxes of heat, freshwater, and momentum far from the equatorial Pacific, which in turn impact SST, salinity, MLD, and ocean currents. Thus, the atmosphere acts as a "bridge" spanning from the equatorial Pacific to other portions of the global oceans, including the WBCs in the North Atlantic and Pacific (e.g., Alexander 1990, 1992; Lau and Nath 1994, 1996, 2001; Alexander et al. 2002).

During boreal winter, when El Niño events typically peak, enhanced cyclonic circulation around the deepened Aleutian low results in anomalous northwesterly winds that advect relatively cold dry air over the westerncentral North Pacific and enhance surface westerlies over the central North Pacific. The resulting anomalous $Q_{\text {net }}$ and Ekman transport create negative SSTAs between $30^{\circ}$ and $50^{\circ} \mathrm{N}$ west of $\sim 150^{\circ} \mathrm{W}$ (Alexander et al. 2002 ; Alexander and Scott 2008). Differences between El Niño and La Niña events for 1985-2007 in a high-resolution SST dataset (Reynolds et al. 2007) are generally negative but highly variable in the KOE region (Fig. 9a), although a longer record of lower-resolution data indicates cooling along $40^{\circ} \mathrm{N}$ and warming to the south of Japan from $20^{\circ}$ to $35^{\circ} \mathrm{N}$ (e.g., Hanawa et al. 1989; Alexander et al. 2002). In addition, the basin-scale wind stress curl anomalies associated with the changes in the Aleutian low induced by tropical variability via the "atmospheric bridge" can remotely force KOE variability via oceanic Rossby waves (section $2 \mathrm{f}$ ).

The wintertime ENSO response also impacts North Atlantic variability and could thus affect the GS. The negative phase of NAO, with anomalous high (low) pressure in the high (mid) latitudes in conjunction with a southward displacement of the storm track along the

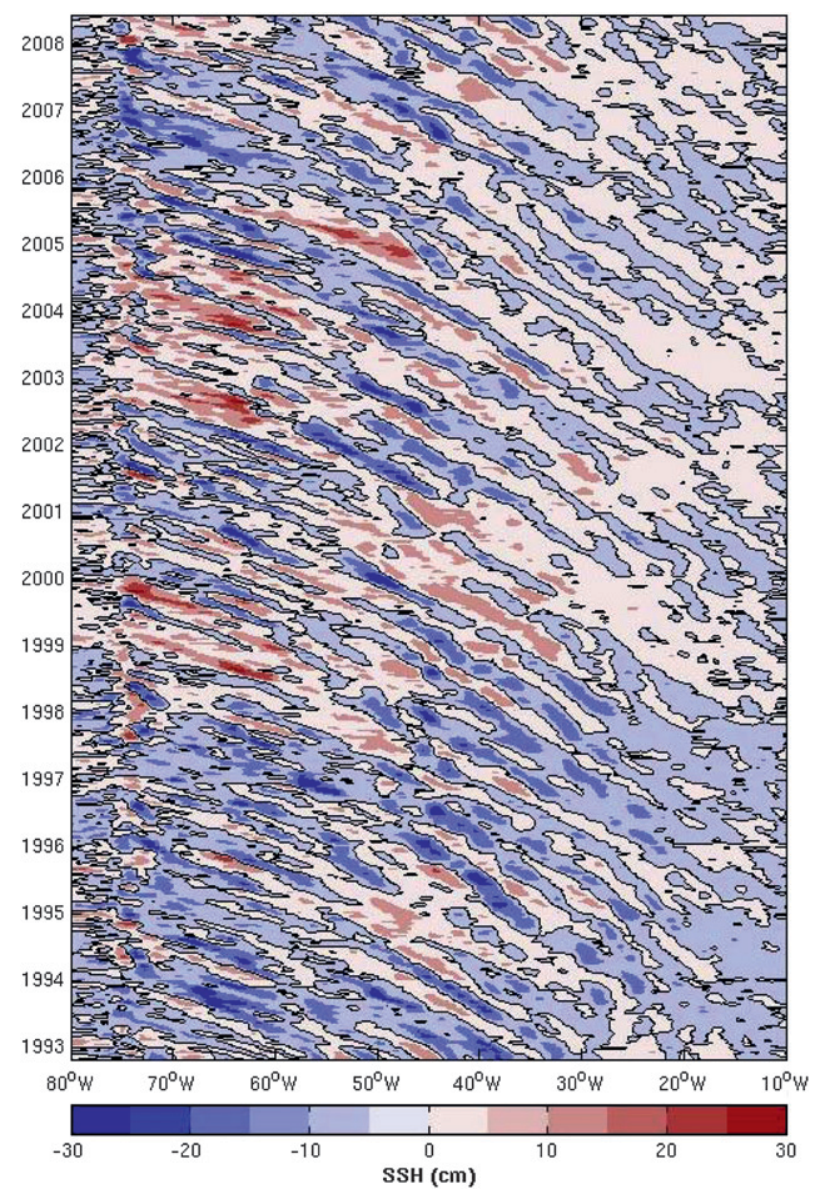

FIG. 8. SSH anomalies along the zonal band of $32^{\circ}-34^{\circ} \mathrm{N}$ in the North Atlantic from the satellite altimeter data. Solid contours indicate zero anomalies.

eastern seaboard, is more prominent during El Niño relative to La Niña events (cf. van Loon and Madden 1981; Pozo-Vázquez et al. 2001; Lau and Nath 2001; Alexander et al. 2006). These atmospheric circulation changes create an SST tripole pattern, with negative anomalies in the midlatitudes flanked by positive anomalies in the subarctic and subtropics (Lau and Nath 2001; Alexander and Scott 2008). High-resolution SST data reveal that although the anomalies extend across the basin, the negative anomalies have the greatest amplitude in the northern Gulf of Mexico and along the northern flank of the GS-NAC west of $45^{\circ} \mathrm{W}$ (Fig. 9a). Model experiments suggest that the bridge-related Atlantic SSTAs have a positive feedback on the overlying atmospheric circulation (Lau and Nath 2001; Mathieu et al. 2004; Alexander and Scott 2008), partly because of the increased (negative) meridional SST gradient along the east coast of the United States that enhances low-level baroclinicity, which is conducive to cyclogenesis (Hoskins and Valdes 1990; Drévillon et al. 2003). 

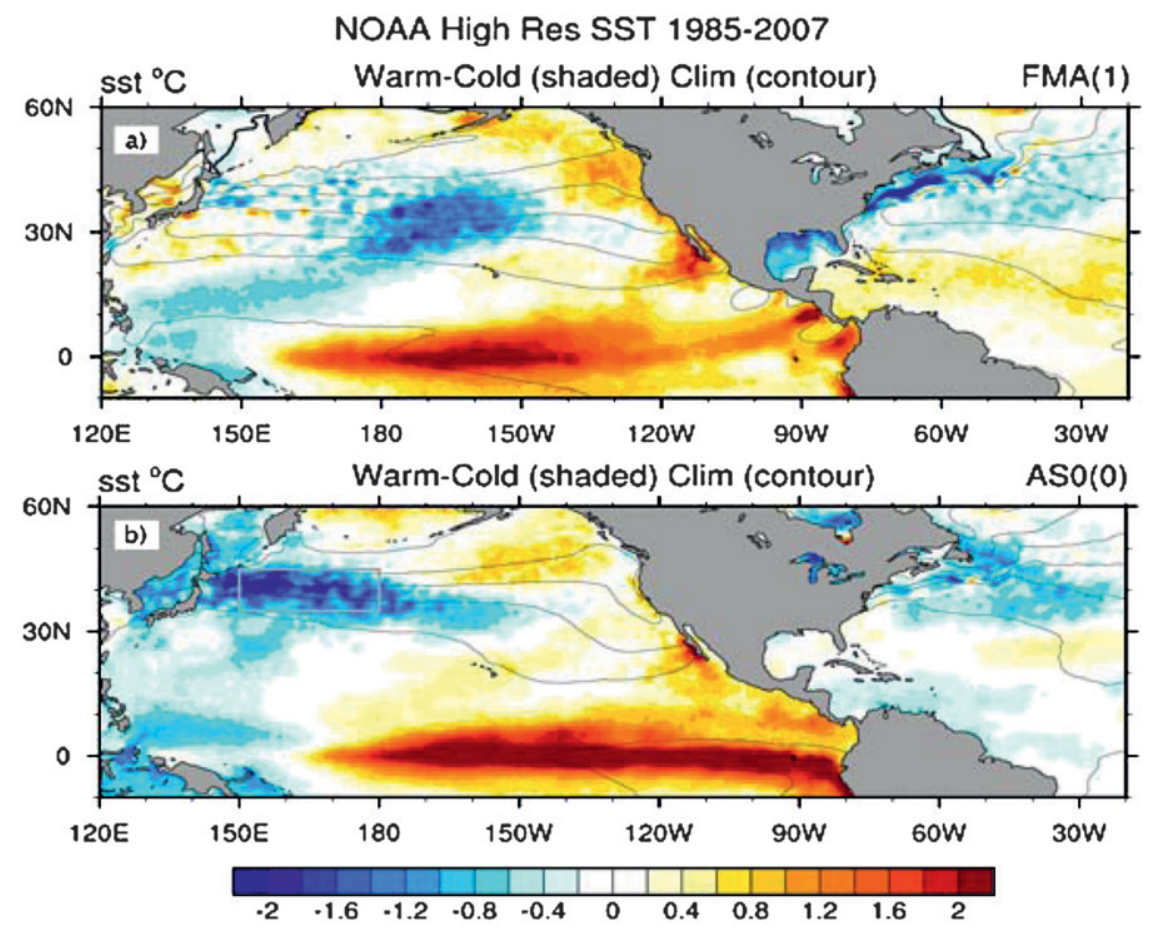

SODA Temp / White MLD 1958-2001

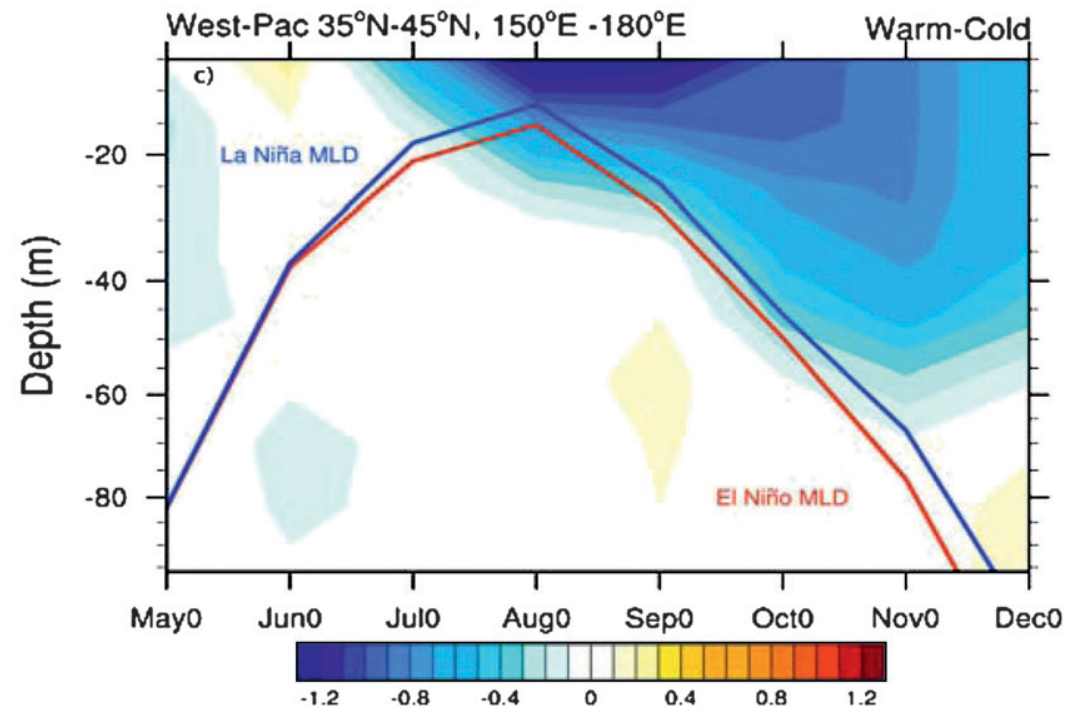

FIG. 9. The composite El Niño-La Niña SST (shading, $\mathrm{CI}=0.2^{\circ} \mathrm{C}$ ) and climatological mean SST (contours, $\mathrm{CI}=4^{\circ} \mathrm{C}$ ) during (a) FMA (year 1), the winter after ENSO peaks, and (b) ASO (year 0$)$, the previous summer. The observations are from the NOAA high-resolution $\left(0.25^{\circ}\right.$ latitude $\times 0.25^{\circ}$ longitude) SST dataset (Reynolds et al. 2007) that spans 1985-2007; 1987, 1991, 1997, 2002, 2006, and 1988, 1998, 1999, and 2005 and were used as year 0 in the El Niño (La Niña) composites. The regions of strong mean SST are associated with the KE and GS. (c) Composite El Niño-La Niña temperature (shading, $\mathrm{CI}=0.2^{\circ} \mathrm{C}$ ) and $\mathrm{MLD}$ during El Niño and La Niña events over the years 1958-2001 as a function of the ENSO cycle in the western North Pacific region $\left[35^{\circ}-45^{\circ} \mathrm{N}, 150^{\circ}-180^{\circ} \mathrm{E}\right.$; gray box in (b)]. The temperatures are from SODA (Carton and Giese 2008) and the MLD from White (1995). 
While most studies of the atmospheric bridge have focused on boreal winter when ENSO and the associated atmospheric circulation anomalies are strongest, ENSOdriven anomalies also occur in other seasons. Over the western North Pacific, a southward displacement of the storm track (along the Baiu front) and jet stream tends to occur in the summer prior to El Niño, which strongly impacts the solar radiation and latent heat flux at the surface (Alexander et al. 2004; Park and Leovy 2004). This surface flux forcing in conjunction with the shallow ML in summer leads to the rapid formation of largeamplitude SSTAs in the KOE (Figs. 9b,c), where these year-to-year variations in SST tend to dominate over decadal-scale variations in summer (Nakamura and Yamagata 1999). El Niño-induced cold SSTAs also occur in the vicinity of the GS during summer.

Teleconnections from the tropical to the North Atlantic are found in AGCM studies (Cassou and Terray 2001; Sutton et al. 2001; Terray and Cassou 2002; Cassou et al. 2004; Rodwell et al. 2004). Drévillon et al. (2003) and Peng et al. $(2005,2006)$ examined the atmosphereocean response to SSTAs specified in the tropical Atlantic in an AGCM coupled to a ML model in the North Atlantic Ocean. The direct atmospheric response to the tropical SSTAs resembles the NAO, consistent with the previous AGCM experiments (Fig. 10). The associated surface heat fluxes and Ekman transport create SSTAs of opposite sign in the mid and high latitudes, with the midlatitude maximum along the GS (Fig. 10). The observational analysis of Frankignoul and Kestenare (2005), however, does not show such teleconnections; rather, it supports an equatorial Atlantic SST influence on the east Atlantic pattern, as modeled by Haarsma and Hazeleger (2007).

Indian Ocean SSTAs can also influence the WBCs through atmospheric teleconnections. During boreal summer an east-west SST dipole in the equatorial Indian Ocean may influence the atmosphere and SST in the western North Pacific (Saji and Yamagata 2003). Likewise, the basinwide anomalies that occur after an ENSO event may impact the Asian monsoon system and the downstream North Pacific through the circumglobal teleconnection pattern (Yang et al. 2009; Xie et al. 2009). In boreal winter, SSTAs generated in the tropical Indian Ocean in response to ENSO may potentially modulate the anomalous Aleutian low generated in direct response to the ENSO SST anomalies in the Pacific (Annamalai et al. 2007). Furthermore, Hoerling et al. $(2001,2004)$ and Bader and Latif (2003) found that long-term warming of the Indian Ocean contributed to the trend in the NAO, which can subsequently impact the GS.

Given that the extratropical ocean response to tropical forcing varies with season, location, and time scale, it is difficult to quantify the impacts of the various mechanisms discussed above on WBC variability. In addition, variability in each of the tropical basins affects the other. Nevertheless, it seems clear that of the three tropical ocean basins, the Pacific has the greatest impact on the Northern Hemisphere WBCs and the Kuroshio in particular. ENSO also has a very strong influence on SSTs over most of the tropics and thus the extratropical response to SST anomalies in the tropical Indian or Atlantic Oceans may be indirectly caused by fluctuations in the tropical Pacific. Statistical analyses, stochastic models, and GCM experiments indicate that about $25 \%-35 \%$ of the SST variability in the KOE region can be attributed to ENSO (e.g., Alexander et al. 2002, 2004; Schneider and Cornuelle 2005). Figure 9 suggests that the atmospheric bridge from the tropical Pacific to the North Atlantic is quite strong, although a quantitative assessment of the full impact of the tropics on the GS region remains to be determined (also see section 5b).

\section{WBCs and the basin-scale climate variability}

\section{a. Decadal SST variability in the WBCs}

Given the importance of WBC SSTAs in atmosphereocean interaction, we examine their structure on interannual and decadal time scales and their role in basin-scale climate variability. The SST variance in the North Pacific $\left(>20^{\circ} \mathrm{N}\right)$ exhibits maxima in the central North Pacific near $35^{\circ} \mathrm{N}, 160^{\circ} \mathrm{W}$ and in the western North Pacific near $40^{\circ} \mathrm{N}$ along the KOE. SSTAs in the central North Pacific have more variance on interannual time scales, while the maximum in the KOE has greater variance at decadal and longer time scales (Fig. 11; see also Fig. 2). Both maxima are reflected in the loading pattern for the PDO (Mantua et al. 1997). The PDO is defined as the leading EOF of monthly North Pacific SSTAs (poleward of $20^{\circ} \mathrm{N}$ ), which selects for the maximum basinwide variance, with the potential for confounding variability created by different processes (see http://www.cdc.noaa.gov/WBC/ for the leading EOF patterns). The pattern-based observational data analyses suggest that both the interannual and decadal time scales of the PDO are related to SSTAs in the tropical Pacific (Nitta and Yamada 1989; Deser and Blackmon 1995; Barlow et al. 2001; Newman et al. 2003; Alexander et al. 2002, 2008; Zhang et al. 1997; Guan and Nigam 2008), but there are also independent signals whose variability is primarily concentrated along the $\mathrm{KOE}$ (Nakamura et al. 1997). Vimont (2005) also suggests that the decadal ENSO-like pattern, which is almost identical to the PDO, can be mostly reconstructed using the spatial pattern associated with interannual ENSO variability but noted that this reconstruction does not reproduce 
a) Specified SST

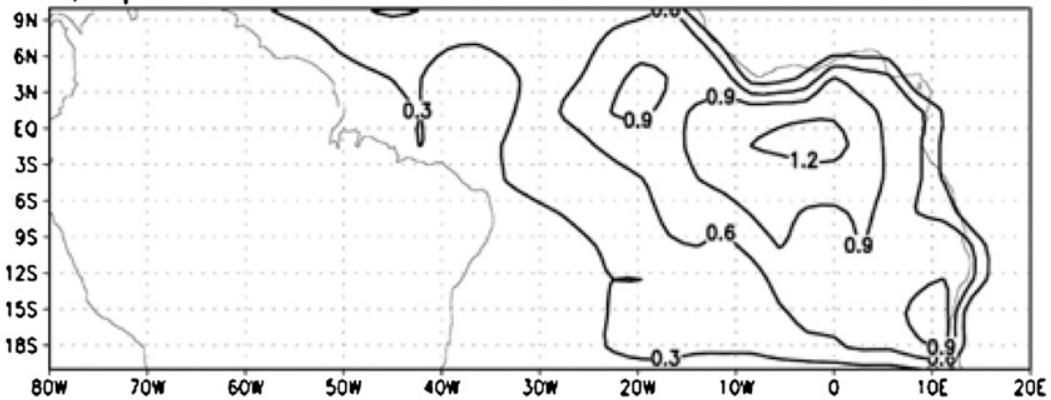

b) $Z 500$

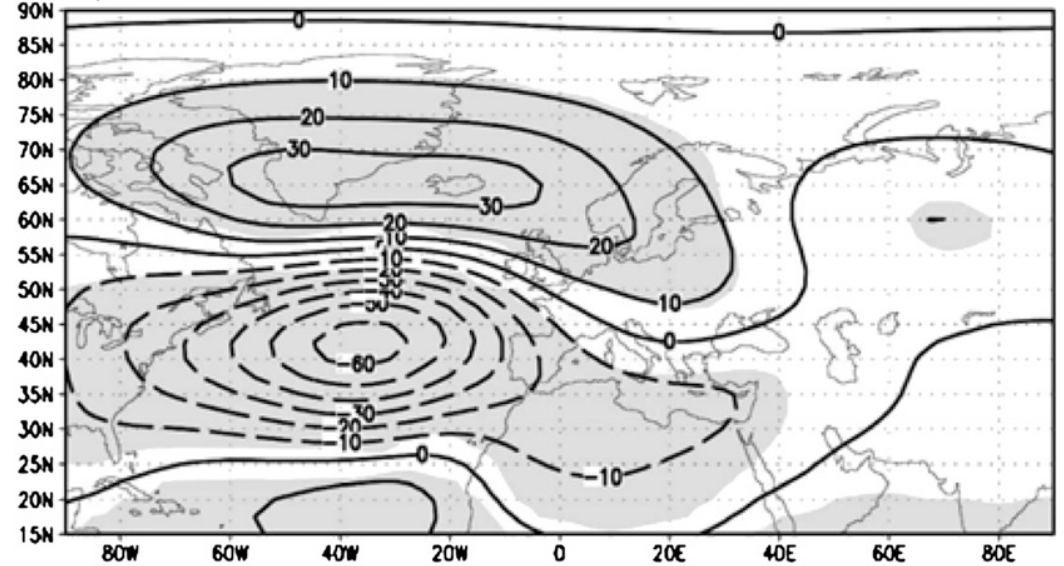

c) Simulated SST

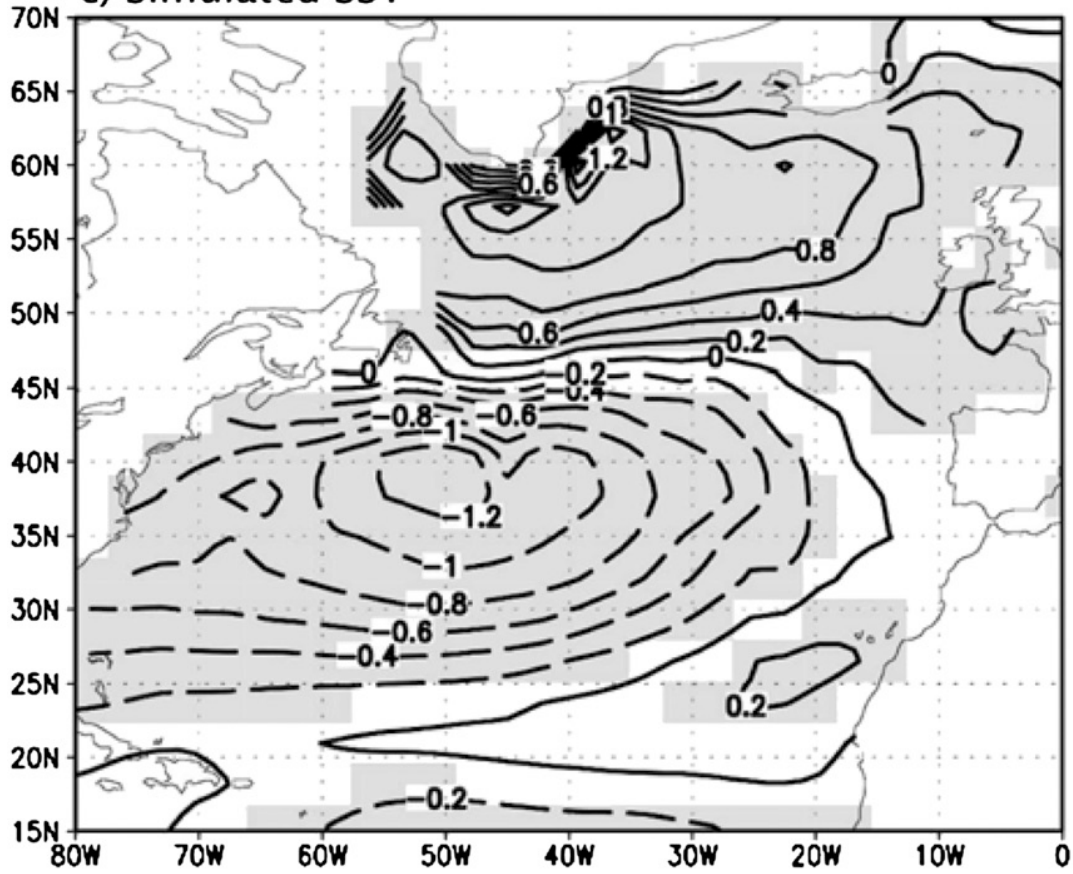

FIG. 10. (a) The tropical SST anomaly $\left({ }^{\circ} \mathrm{C}\right)$ used to force the AGCM-mixed layer model. (b) The 500-hPa response (m), during FMA given by the ensemble mean difference between simulations with positive and negative $[-1 \times$ those in (a)] tropical SST anomalies. (c) SST response in the 75-m mixed layer model driven by surface fluxes and Ekman heat transport. Shading denotes areas where the response is significant at the $95 \%$ level as estimated by a Student's $t$ test. (Adapted from Peng et al. 2006.) 

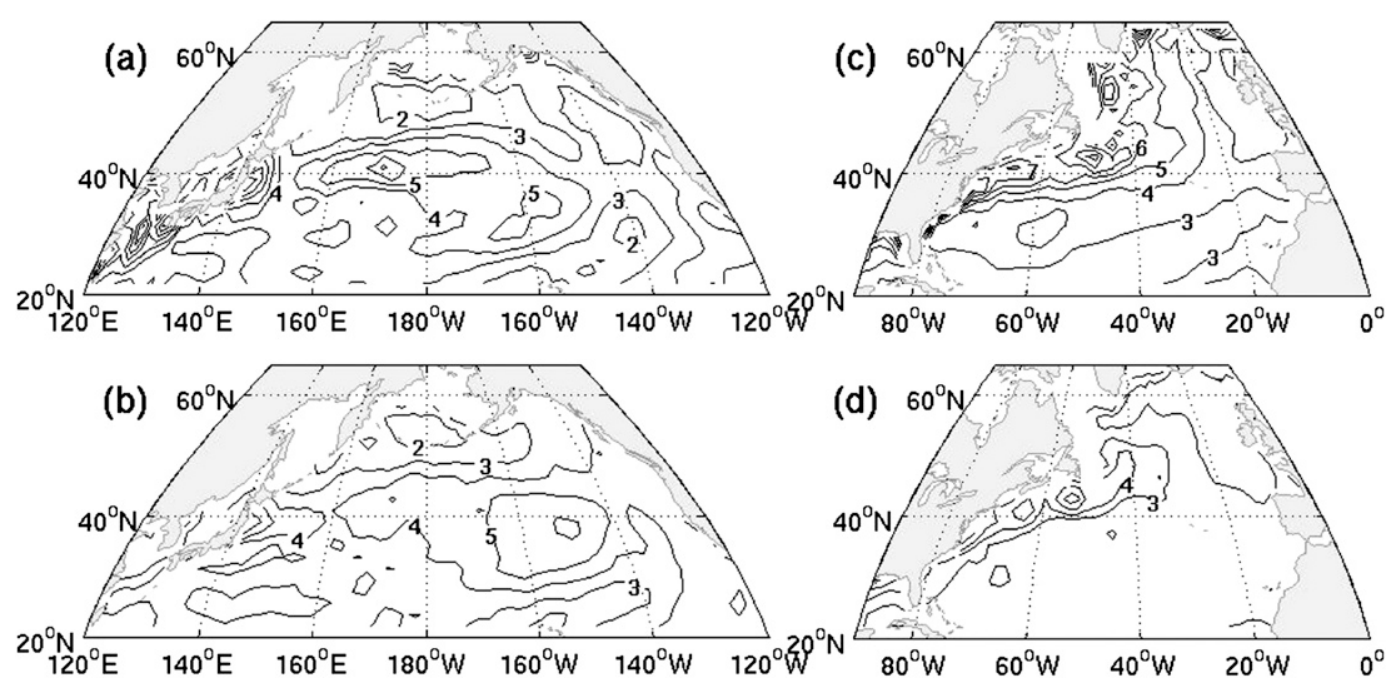

FIG. 11. (a) Standard deviation of January-March (JFM) SST from NCEP-NCAR reanalysis I for 1948-2006. SST is low-pass filtered to retain periods $>7$ years. CIs are $0.1^{\circ} \mathrm{C}$. (b) As in (a), but high-pass filtered to retain periods $<7$ years. Both (a) and (b) are reproduced based on Fig. 1 of Nakamura et al. (1997). (c),(d) As in (a),(b), but for the North Atlantic and with a 5-yr cutoff for the low-pass and high-pass filters. Five years were used for the cutoff of the low-pass and high-pass filters instead of 7 years as in the North Pacific to reflect the smaller basin size and thus a relatively shorter time for the Rossby wave for the adjustment of the basin via first baroclinic mode Rossby waves. However, consistent results are obtained from different cutoff between 5 and 10 years.

the enhanced decadal variability in the KOE. Schneider and Cornuelle (2005) found that on interannual time scales the PDO as a whole is forced about equally by heat fluxes associated with random fluctuations in the Aleutian low (PNA pattern) and by ENSO teleconnections, while on a decadal time scale the PDO is also influenced by wind-driven ocean circulation changes whose contribution is maximum along the KOE. Most of the decadal SST variability in the KOE can be reproduced in a hindcast experiment in which an OCGM is forced by the observed wind stress but without any thermal forcing (Xie et al. 2000). Low-frequency SST variability in the North Pacific including the KOE may also be influenced by teleconnections from the western tropical PacificIndian Ocean on decadal time scales (Deser et al. 2004; Newman 2007; Guan and Nigam 2008).

In the North Atlantic, decadal SST variability is enhanced along the GS and its extension east of $\sim 40^{\circ} \mathrm{W}$ (Figs. 11c,d). The maximum SST variability occurs in the Slope Water region slightly north of the GS, where the climatological SST gradient is strongest. In contrast to the North Pacific, interannual variability does not exhibit a distinct maximum in the central basin but is collocated with decadal variability along the GS. The leading EOF of North Atlantic $\left(15^{\circ}-75^{\circ} \mathrm{N}\right)$ SST has maximum variance in the GS region, representing multidecadal modulations superimposed on a long-term trend since 1900 (Deser and Blackmon 1993; Kushnir 1994). This variability does not appear to be forced by local winds. The second EOF, the North Atlantic tripole, has anomalies of one sign east of Newfoundland and in the northern tropics and anomalies of the opposite polarity off the southeast coast of the United States. The tripole pattern is well correlated with local wind and surface heat flux variability, which is mostly controlled by the NAO (Cayan 1992), and the associated time series has a small spectral peak at around 9-12 years. Using multichannel singular spectrum analysis (MSSA) of the North Atlantic SST from 1870 to 2004, Álvarez-García et al. (2008) found that the leading MSSA mode indicates a basinwide warming trend. The combination of the second and third modes exhibits low-frequency variability and is basically equivalent to the Atlantic Multidecadal Oscillation (AMO), which is defined by the SST averaged over the North Atlantic from the equator to $70^{\circ} \mathrm{N}$ (Enfield et al. 2001). The subsequent modes describe a quasidecadal oscillation with a spatial structure similar to the tripole pattern. The leading EOFs based on highresolution $\left(0.25^{\circ}\right) \mathrm{SST}$ data for 1982-2008 indicate that the variance is concentrated along the GS for the three modes, while the patterns are somewhat different from the previous studies based on longer records (Fig. 12). The first mode represents a warming trend over the past 27 years associated with the AMO (correlation $=0.92$ ). The second and third modes exhibit interannual variability. Note that the leading EOF of SSH in the North Atlantic also exhibits the variance concentrated along the GS (Häkkinen and Rhines 2009). 


\section{b. Oceanic dynamics and decadal variability}

Frankignoul et al. (1997) provides a theoretical framework for understanding decadal and longer time scale variability in the extratropical WBC SSTs (i.e., stochastic weather fluctuations generate $\nabla \times \boldsymbol{\tau}$ with a white frequency spectrum that excites baroclinic Rossby waves in the ocean interior). As the Rossby waves propagate westward, they integrate the stochastic forcing to increase the variance and dominant period of dynamic ocean properties until reaching a maximum near the WBC. This mechanism produces red spectra in thermocline depth or SSH variance without a preferred frequency, but spectral peaks may occur if Rossby waves are forced by $\nabla \times \tau$ with a more complex spatial-temporal structure or by additional ocean dynamics. The spatial resonance mechanisms could generate a decadal peak in the ocean forced by stochastic atmosphere (Saravanan and McWilliams 1997; Jin 1997). For example, resonance can occur between a dipole forcing and an ocean anomaly that propagates either via Rossby waves or via advection by the mean current. In addition, a weak coupling with the atmosphere can enhance decadal variance (Jin 1997; Neelin and Weng 1999; Ferreira et al. 2001). Qiu (2003) suggested that because of the latitudinal dependence of the Rossby wave propagation speed, coherent wind stress forcing could generate oppositely signed SSH anomalies on either side of the KE, altering the strength of the KE jet on a time scale of $\sim 12$ years. Marshall et al. (2001) and Qiu et al. (2007) proposed that ocean-atmosphere coupling can generate a decadal spectral peak without spatial resonance (see section 3d). There are also nonlinear oceanonly decadal modes in eddy-resolving high-resolution models forced by climatological winds, but they have only been found in highly idealized ocean models (Dewar 2001; Berloff et al. 2007; Kravtsov et al. 2007), and it remains to be shown whether they are present in observations or more realistic models.

\section{c. Surface heat flux damping and implications}

Decadal WBC SSTAs are primarily forced by ocean dynamics, especially for time scales longer than a few years (Seager et al. 2001; Tanimoto et al. 2003; Dong and Kelly 2004), and damped by surface heat fluxes, implying anomalous heat transfer to the atmosphere. The flux anomalies may have a significant impact on the atmosphere beyond the local boundary layer via changes in the storm track, as hypothesized by Chang et al. (2002), Kushnir et al. (2002), Nakamura et al. (2004), and Bengtsson et al. (2006). The mean surface storm track (represented using the 2-8-day bandpass-filtered daily surface latent heat flux variability) and the maximum yearto-year storm track variability are very closely aligned with
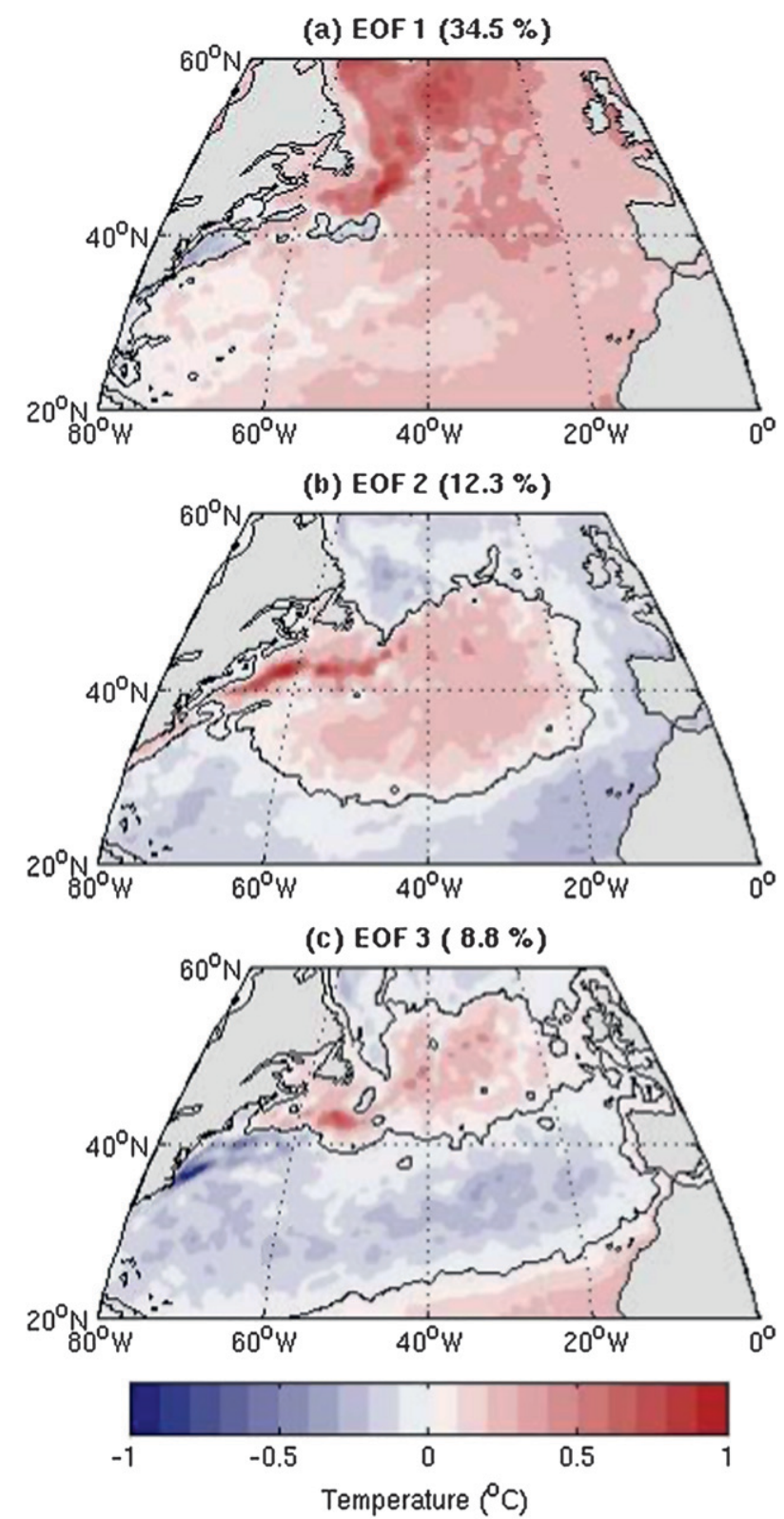

FIG. 12. Leading EOFs of winter [November-March (NDJFM)] SST for 1982-2008 based on the NOAA high-resolution $\left(0.25^{\circ}\right.$ latitude $\times 0.25^{\circ}$ longitude) SST, version 2 (http://www.ncdc.noaa.gov/ $\mathrm{oa} / \mathrm{climate} / \mathrm{research} / \mathrm{sst} / \mathrm{oi}$-daily.php). Note that the trends are not removed before calculating the EOFs. The amplitudes correspond to the $1 \sigma$ change in the corresponding principal component time series. The fraction of total variance explained by each mode is shown in the bracket. The zero contours are plotted in black.

the GS and KOE (Fig. 13). Joyce et al. (2009) found that meridional shifts in the surface storm track occur in conjunction with those of the GS and KOE on interannual and longer time scales. The large-scale atmospheric circulation response appears to be more sensitive to the SSTAs in the WBC regions compared to those in the 

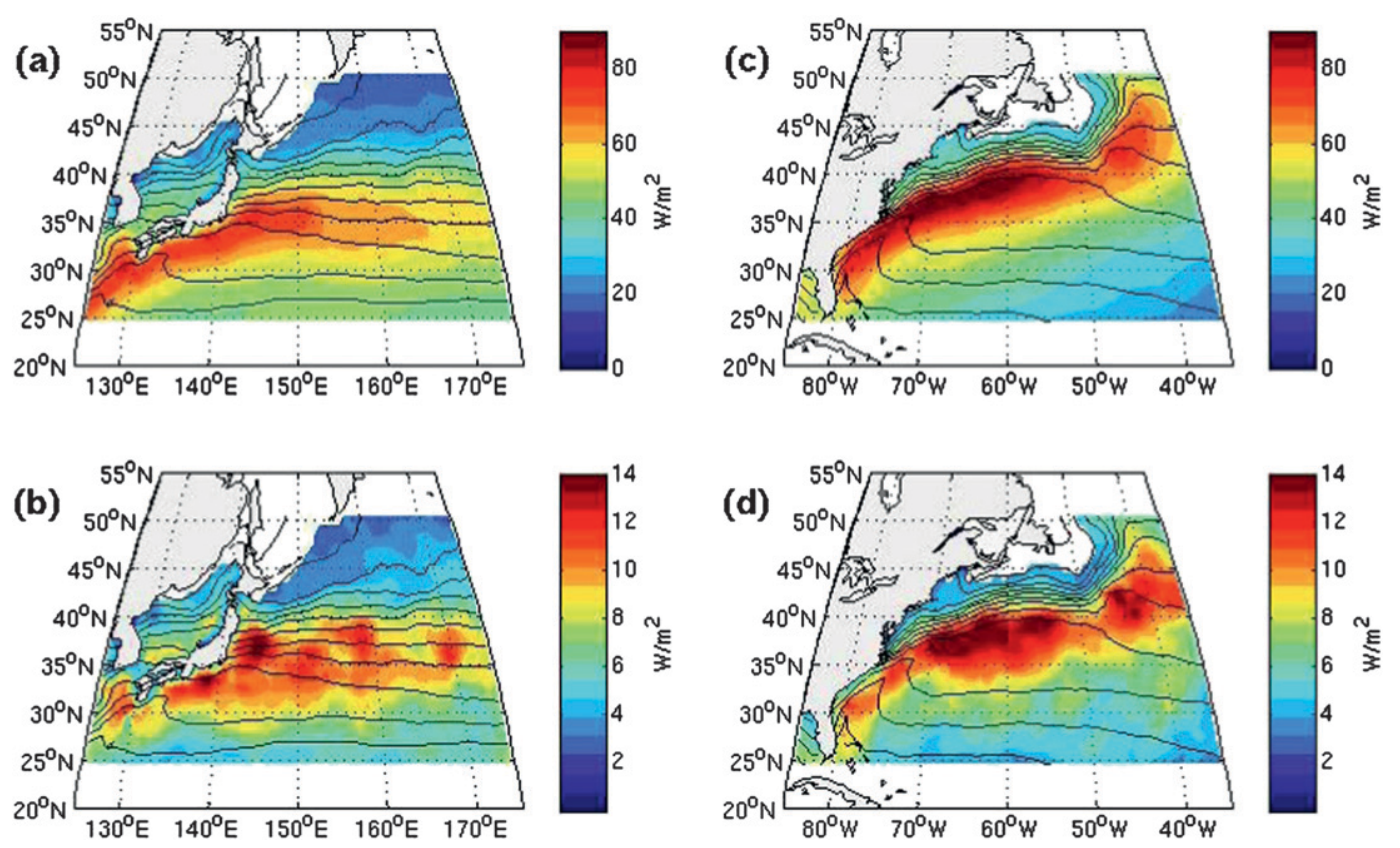

FIG. 13. (a) The 22-yr mean of each winter's (JFM) standard deviation of the 2-8-day bandpass-filtered daily latent heat flux from the objectively analyzed air-sea fluxes (OAFlux) for 1983-2004 (Yu et al. 2008). Contours are the climatological mean winter (JFM) SST with $2^{\circ} \mathrm{C}$ interval. (b) Interannual standard deviation of each winter (JFM)'s standard deviation of the 2-8-day bandpass-filtered daily latent heat flux. (c),(d) As in (a),(b), but for the North Atlantic. The figure is reproduced from Figs. 7 and 12 of Joyce et al. (2009).

interior of the basin because of the proximity to the storm track (Peng and Whitaker 1999). Nonetheless, the AGCM response to specified extratropical SSTAs or to prescribed heat flux convergence in a ML model coupled to an AGCM varies among models, and most observational analyses suggest that the atmospheric response to midlatitude SSTAs is of modest amplitude (this is discussed further in section $5 b$ ).

\section{d. Decadal variability in atmosphere-ocean coupled general circulation models}

Extratropical climate variability can be difficult to assess using observations or single component models, such as OGCM hindcasts, because of the limited sampling. Coupled climate models generally indicate that oceanatmosphere interaction in WBC regions is a key factor in generating extratropical decadal variability. Latif and Barnett $(1994,1996)$ first suggested that decadal variability in the North Pacific could be attributed to a cycle involving unstable ocean-atmosphere interaction between the subtropical ocean gyre circulation and the Aleutian low pressure system. When, for instance, the Aleutian low was anomalously deep, the subtropical ocean gyre was spun up by anomalous wind stress with a delay of about 5 years due to Rossby wave adjustment. This caused greater transport of warm water into the KOE, leading to positive SSTAs. The atmospheric response to the positive SSTAs consisted of a weakened Aleutian low, which initiates the opposite phase of their 20-yr oscillation. In the model, the associated $Q_{\text {net }}$ anomalies in the KOE region reinforced the initial SSTAs so that the ocean and atmosphere acted as a positive feedback system, but this is at odds with observations, and the subsequent modeling studies consistently showed that the $Q_{\text {net }}$ feedback is negative in WBCs.

Pierce et al. (2001) investigated Pacific decadal variability in two coupled GCM simulations and in an AGCM coupled to a slab ocean ML model without ocean dynamics. While both coupled GCMs generated statistically significant decadal variability in SST along the KOE, the AGCM ML simulations had no spectral peak, indicating that ocean dynamics and atmosphere-ocean coupling enhanced decadal variability in SST above the red noise background. Furthermore, they found that meridional shifts of the ocean front were responsible for the SSTAs in the KOE and that $Q_{\text {net }}$ damps the SSTAs in the KOE, consistent with observations. Their AGCM experiments forced with prescribed SSTAs taken from the coupled model simulation indicated that the $\boldsymbol{\nabla} \times \boldsymbol{\tau}$ response to the KOE SSTAs could excite the oceanic Rossby waves in the central Pacific necessary for decadal variability. Similar results were found by Kwon and Deser (2007) in an analysis of North Pacific decadal variability in a 650 -yr coupled GCM integration. The 
crucial result here was that SSTAs induced in the vicinity of the KOE front due to prior fluctuations in $\nabla \times \tau$ in the central Pacific generated a response in the atmospheric circulation including $\nabla \times \boldsymbol{\tau}$ anomalies of opposite sign to the prior $\nabla \times \boldsymbol{\tau}$ anomalies, thereby acting as the negative feedback. A similar mechanism was also identified by Wu et al. (2005), using a "model surgery" approach, which allows or deactivates atmosphere-ocean coupling in a selected region, and by Qiu et al. (2007), who used a linear Rossby wave model and statistical models for the influence of SSH on SST and for the $\nabla \times \boldsymbol{\tau}$ response to KOE SSTAs.

In addition to the $\sim 20$-yr decadal variability, some model simulations exhibit significant 40-50-yr multidecadal peaks in the basinwide North Pacific SST with high correlations to the tropical Pacific SST (Kwon and Deser 2007; Zhong et al. 2008), which is also suggested from observations (Nakamura et al. 1997; Minobe 1997; Deser et al. 2004). Zhong et al. (2008) and Zhong and Liu (2009) recently suggested that the multidecadal variability in the coupled GCM simulation results from the very slow Rossby wave adjustment in the subpolar North Pacific, which subsequently influences ocean-toatmosphere feedback in the KOE and in the tropics.

Although earlier studies suggested that North Atlantic decadal variability in SST was primarily reflecting a passive response to the atmospheric forcing, with only hints of active ocean-atmosphere coupling (Zorita and Frankignoul 1997; Grötzner et al. 1998), evidence is growing that the ocean-atmosphere coupling plays a critical role in sustaining North Atlantic decadal oscillations (Wu and Liu 2005). Marshall et al. (2001) employed an observation-based analytic model to show the oceanatmosphere coupling based on either the Rossby wave dynamics or interaction between the GS and MOC could generate decadal variability in the North Atlantic. In Bellucci et al. (2008), the dominant mechanism was shown to involve gyre adjustment to wind stress curl forcing, SST advection along the GS and the NAC, and a positive feedback between SST and the NAO. The role of the MOC appeared to be secondary on a decadal scale, but the dynamics at lower frequencies are more complex in the North Atlantic because of the interaction between the GS and the MOC (e.g., Delworth et al. 1993; Timmermann et al. 1998; Dong and Sutton 2005), as further discussed in section $5 \mathrm{~d}$.

\section{Performance of climate models on simulation of WBC variability}

In the previous sections, we have examined WBC variability in observations and climate models. Here, we assess the ability of numerical models to reproduce the
WBCs and the processes that impact their variability, with a focus on the ocean. At a resolution of $1 / 10^{\circ}$ or better for the ocean model, the WBCs tend to separate from the coast in approximately the right locations, with realistic magnitudes and structure. In contrast, the resolution in typical climate models (on the order of $1^{\circ}-2^{\circ}$ ) is not adequate to represent the dynamics necessary for the correct location or strength of the current extensions. Here, we examine the progress that has been made using high-resolution models and the consequences of inadequate resolution in the current generation of climate models.

\section{a. High-resolution ocean simulations}

The challenges for ocean models in representing both the mean and the variability of the GS and KOE are different. Observations indicate that the KE's path variability can be tied largely to wind forcing (section 2), which suggests that interannual and longer variability in currents, temperature, heat content, and thermoclinewater mass structure should be reproducible. As discussed in section $2 \mathrm{a}$, the $\mathrm{KOE}$ region contains two fronts: the KE front, characterized by a sharp SSH gradient but weak SST gradient and the subarctic (OE) front, with a large SST gradient but a weak SSH gradient. The distinction between these two fronts can only be found in high-resolution ocean models [e.g., see Nonaka et al. (2006), and the SSH from the Hybrid Coordinate Ocean Model (HYCOM) simulation discussed by Kelly et al. (2007)]. However, both the Nonaka et al. (2006) and Maltrud and McClean (2005) simulations show a persistent large meander near $137^{\circ} \mathrm{E}$, which does form in nature but is not as persistent as in the model simulations.

The high-resolution model study by Taguchi et al. (2005) suggests that an eddy-driven intrinsic mode of variability in $\mathrm{KE}$ is modulated by the wind-driven Rossby waves. The deterministic nature of the wind-driven mode suggests that this mode of variability could be reproduced even in low-resolution models. By contrast, the intrinsic mode is likely more difficult to accurately represent, especially at low resolution. Kelly et al. (2007) find that while the mean state in the North Pacific is well represented in a high-resolution simulation using HYCOM, the variability is not as well represented as in the OFES simulation analyzed by Taguchi et al. (2007) and Nonaka et al. (2006). This suggests that accurately representing the intrinsic mode of variability is nontrivial and may depend on the details of the model parameterization of subgrid-scale processes and vertical discretization, among others.

The interaction of the GS with the DWBC requires that the nonlinear dynamics of the surface currents and the formation regions, transport, properties, and dynamics of the DWBC must be adequately represented. Thus, 

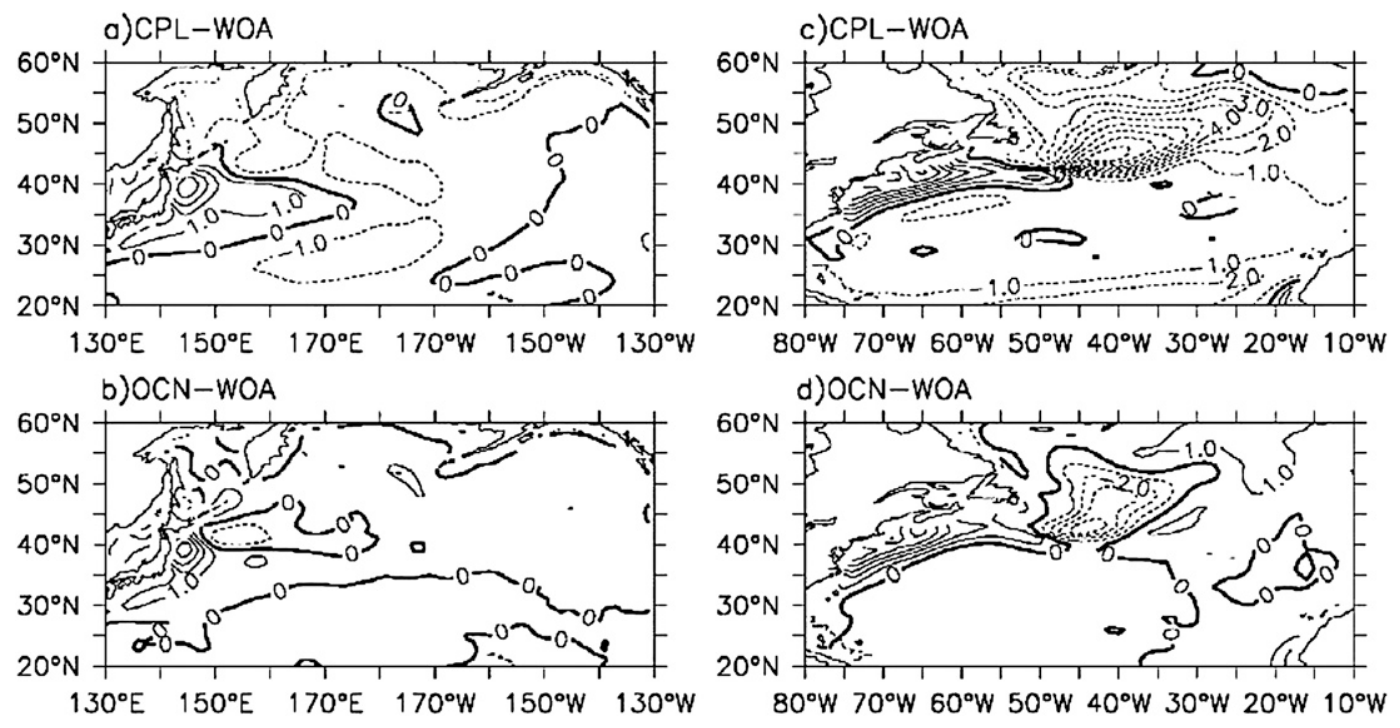

FIG. 14. Difference between mean SST in the (a),(b) North Pacific and (c),(d) North Atlantic for (a),(c) CCSM3 and (b),(d) an ocean-only simulation using the ocean model in CCSM3.

representing the paths of the GS and NAC and their penetration into the subtropical and subpolar gyres remains challenging even for the most highly resolved global models. Regional simulations of the North Atlantic at $1 / 10^{\circ}$ resolution (Smith et al. 2000) show large improvement over eddy-permitting simulations at $1 / 4^{\circ}$ to $1 / 3^{\circ}$ resolution. Although slightly too far to the south upstream of $65^{\circ} \mathrm{W}$, the downstream path of the GS is in excellent agreement with observationally derived estimates. The $\mathrm{SSH}$ variability is also improved, although the maximum is displaced upstream even in the high-resolution model with overestimated meridional extent and underestimated penetration into the eastern basin. When the model is then run in the global domain, however, the results are degraded in the North Atlantic (Maltrud and McClean 2005). In particular, the NAC does not turn to the north along Newfoundland but rather penetrates to the east. The SSH variability maximum is again displaced upstream of the observational counterpart. The global model does not directly simulate sea ice extent, but instead both SST and SSS are strongly relaxed to the climatology in regions of climatological sea ice cover. A comparison of the two model simulations indicates that constraining the North Atlantic at the northern boundary by relaxation to climatology throughout the water column results in a better representation of the GS and NAC because of the controlling role of the DWBC.

\section{b. Simulations of the Kuroshio and Gulf Stream at non-eddy-permitting resolution}

The WBCs in low-resolution climate models are known for persistent biases in both ocean-only (i.e., an ocean model forced by observed atmospheric fields) and coupled ocean-atmosphere simulations that result in qualitative errors in various aspects of both the subtropical and subpolar gyres in the North Pacific and North Atlantic. The weak and diffuse boundary current results in biases of the heat transport by the current and thus biases in SST and sea surface salinity (SSS). There are also associated errors in surface buoyancy fluxes, MLD, and STMW formation in both basins. These biases are independent of the model used and occur in both ocean-only and coupled simulations, with the errors in general becoming enhanced in coupled simulations. We focus our discussion mainly on two Intergovernmental Panel on Climate Change (IPCC) class models that have been evaluated in the literature, version 2.1 of the coupled climate model (CM2.1) produced by the Geophysical Fluid Dynamics Laboratory (GFDL) and version 3 of the Community Climate System Model [CCSM3; National Center for Atmospheric Research (NCAR)].

The Kuroshio is too wide in both CM2.1 (Gnanadesikan et al. 2006) and CCSM3 (Large and Danabasoglu 2006). This reflects the lack of the distinction of the two fronts in the KOE, but in CCSM3 there is a reasonable representation (within the grid resolution) of its southern edge and positioning of its extension. The poleward displacement of the northern edge leads to a 1-psu saline bias and $4^{\circ} \mathrm{C}$ warm bias (Fig. 14a): Correspondingly, the local heat loss to the atmosphere is excessive by $\sim 100 \mathrm{~W} \mathrm{~m}^{-2}$. An ocean-only simulation (i.e., an ocean model forced by repeated annual forcing from observation; see Thompson and Cheng 2008 for details) gives very similar results, with too warm water upstream and a too cool region to the 
a. WOA

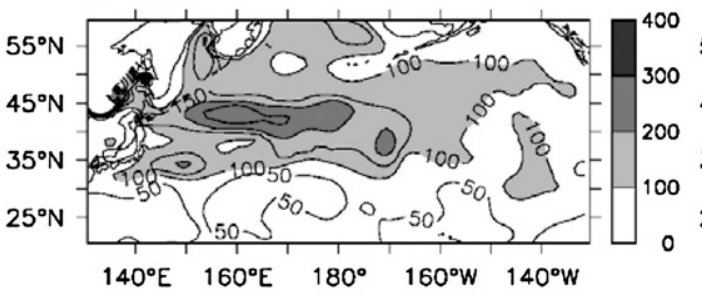

b. CPL

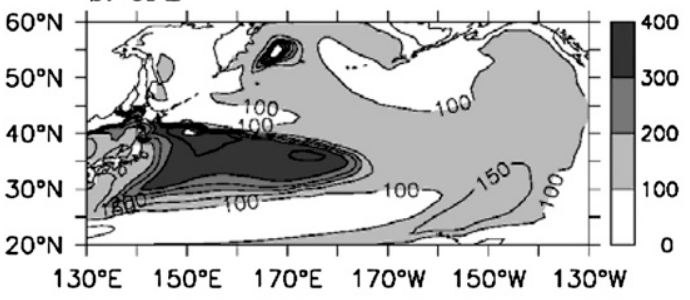

c. $\mathrm{OCN}$

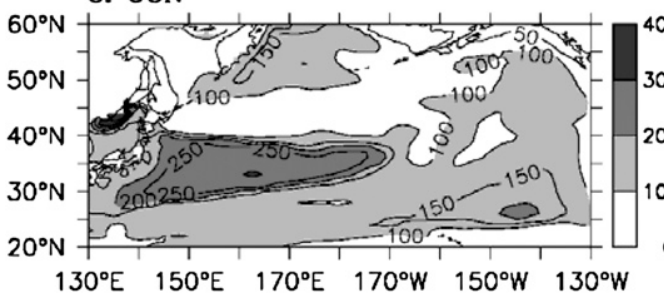

\section{d. WOA}

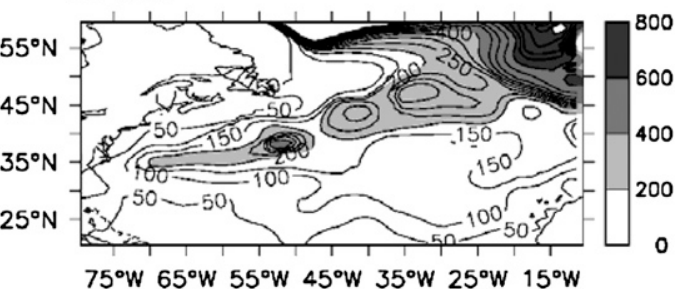

e. CPL

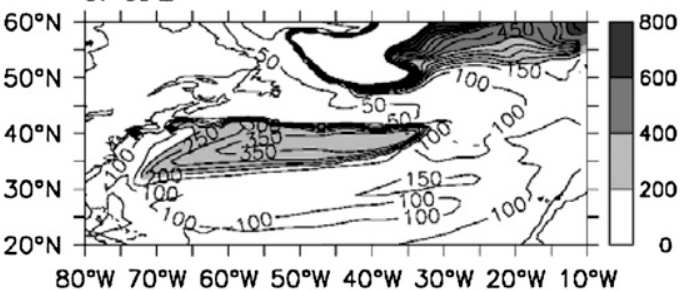

f. $\mathrm{OCN}$

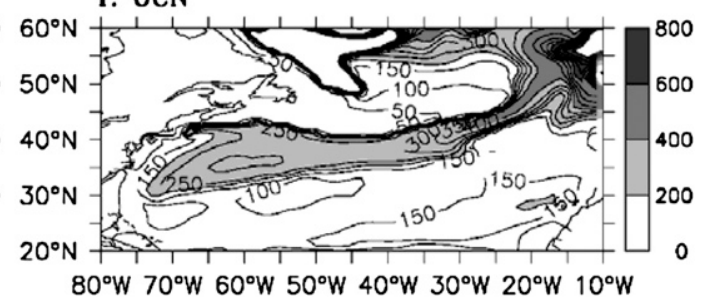

FIG. 15. MLD in the (a)-(c) North Pacific and (d)-(f) North Atlantic from (top) observations, (middle) a coupled ocean-atmosphere version of CCSM3, and (bottom) an ocean-only version of the same model.

north and east, indicating a lack of warm advection by the KE (Fig. 14b). In CM2.1, the Kuroshio penetrates too far to the north and the SST is too warm in both Northern Hemisphere subtropical gyres near the WBCs but too cool in the interior (Delworth et al. 2006). However, Gnanadesikan et al. (2006) note an entrainment of overly cold subpolar water entering the subtropical thermocline around the boundary of the subtropical gyre to the northeast, which is also likely associated with advection errors in the WBC. Thompson and Cheng (2008) show that the lack of advection of warm water from the boundary into the interior in CCSM3 results in errors in MLD along the KOE (Figs. 15a-c). In the high-resolution model (Nonaka et al. 2006) and in nature, advection restratifies the KE such that the maximum MLD in winter is inhibited.

The separation of the two fronts in KOE has consequences for not only the structure of the local MLD but also the formation of mode waters. There are two distinct mode waters generated in the KOE: the CMW formed in the mixed water region between the $\mathrm{KE}$ and $\mathrm{OE}$ fronts and STMW formed south of the KE front (Yasuda 2003). Low-resolution models cannot reproduce the two separate fronts (see, e.g., Ladd and Thompson 2001), causing the two mode waters to coalesce into a single water mass. This results in a pervasive bias in the structure of the subtropical gyre. The formation regions of CMW and STMW are not distinct in CCSM3, such that only the one mode water forms (akin to the CMW) south of the KE in the model (Thompson and Cheng 2008). Gnanadesikan et al. (2006) also acknowledge that the mode water errors in CM2.1 cause problems in thermocline structure in the subtropics.

As in the North Pacific, the wind stress curl controls the location of the gyre boundary in the North Atlantic, and thus with improvements in the wind the WBC is also improved. However, the GS tends to be too zonal after leaving the coast and thus fails to feed properly into the NAC (Fig. 14c). This complex current structure is known as the Northwest Corner. As in the North Pacific, the western boundary errors propagate into the interior to create a local maximum in the RMSE in the top 1500-m temperature near the GS and the Northwest Corner in CM2.1 (Gnanadesikan et al. 2006). Delworth et al. (2006) show that the overflow in CM2.1 drives an unrealistically vigorous deep meridional flow. This may help move the separation point of the GS to within $100 \mathrm{~km}$ of its correct location (Molinari et al. 2008), although that does not necessarily lead to a realistic simulation of the Northwest Corner. 
In CCSM3, model biases in SST quickly develop in the northwest Atlantic, where subpolar surface water displaces the warm, salty water of the NAC (Large and Danabasoglu 2006). In the subpolar North Atlantic south of Greenland, salinity is more than 4 psu too fresh and $10^{\circ} \mathrm{C}$ too cold. The counteracting ocean heat flux bias is $\sim 150 \mathrm{~W} \mathrm{~m}^{-2}$. Thus, the unrealistic zonal path of the GS leads to biases in SST and SSS that are larger in magnitude and spatial scale than those associated with the Kuroshio (Figs. 14c,d). Recent work by Yeager and Jochum (2009) shows that an ocean-ice coupled simulation using the ocean component of CCSM3 leads to some improvement in the representation of the Northwest Corner over that in an ocean-only simulation because of reduced errors in the interior subpolar gyre. This confirms the importance of coupling between the GS and subpolar North Atlantic through the DWBC.

Coupled modes of variability and intrinsic variability have been investigated in both the North Pacific and North Atlantic, with many such modes of variability originating in either the GS or KE as discussed in section 3d. However, Dawe and Thompson (2005) show that there can be an artificially enhanced mode of variability in lowresolution ocean models that results from longwave baroclinic instability in the return flow of the subtropical gyre, whose amplitude increases with decreasing resolution and increasing viscosity. However, longwave baroclinic instability has also been implicated for decadal modes of variability in idealized studies of the North Atlantic (Colin de Verdière and Huck 1999; Huck and Vallis 2001), and this mode increases in magnitude with decreasing viscosity. In the latter calculations, relative vorticity can be ignored, and the decadal mode arises from longwave baroclinic instability in the presence of constant heat flux surface boundary conditions. The latter mode occurs in the northwest corner of the model domain and is linked to variability in the MOC, but it has less connection to the WBC. In addition, the mode is robust to increases in resolution (Huck et al. 2001). This and other modes of variability need to be investigated further to determine how robust they are with more realistic ocean geometry, atmospheric forcing, and resolution.

The interannual SST variability appears to be unrealistically strong near the GS and KE in both CCSM3 and CM2. In a 100-yr control simulation of CM2, for example, interannual SST variability maximizes along $\mathrm{KE}$, with its amplitude exceeding $2^{\circ} \mathrm{C}$ (Delworth et al. 2006), while 50 years of observation from version 2 of the Hadley Centre-Climate Research Unit (HadCRUTv2) SST gives a maximum that is less than $1^{\circ} \mathrm{C}$. Likewise, there is a local maximum of similar magnitude south of Greenland. Although improved somewhat, especially in the North Atlantic, version 2.1 of CM simulates a local maximum of SST variance that is still too strong. A similar result was found in version 3 of the Hadley Centre Climate Model (HadCM3), in which RMS SST variability is much stronger than that calculated from observations (Collins et al. 2001). Furthermore, the North Pacific decadal variability in CCSM is also too strong over the KOE. There are several possible sources of this overexpression of midlatitude decadal variability, including a response that is amplified by the width and excess concentration of subtropical warm advection near the western boundary.

\section{c. Atmospheric simulations}

A comprehensive review of current state-of-the-art climate models is provided by the Climate Change Science Program (CCSP; Bader et al. 2008). Atmospheric models used in coupled GCMs are suited for a variety of purposes ranging from understanding decadal-scale climate variability (e.g., Kwon and Deser 2007) to projections of midlatitude storm tracks in association with global warming (e.g., Geng and Sugi 2003; Ringer et al. 2006; Nishii et al. 2009). These types of studies are feasible because all the present IPCC climate models have enough resolution to represent atmospheric synopticscale disturbances (Bengtsson et al. 2006), and some of them are able to replicate the mean and variability in the climate over the midlatitude oceans on the basin scale. Over the Atlantic, for example, many IPCC models tend to overestimate the pressure variance associated with the Arctic Oscillation (AO) or NAO (Miller et al. 2006). Oshima and Tanimoto (2009) found that the atmospheric teleconnectivity between the tropics and midlatitudes varies from one IPCC model to another, leading to substantial model dependency on the reproducibility of the PDO. Nishii et al. (2009) found that midwinter suppression of storm track activity, as a subtle but unique feature of the seasonal cycle over the western North Pacific, is reproduced in 8 out of the 19 IPCC climate models, in which the jet stream and winter monsoon are simulated well. In summer, the climatological position of the simulated Baiu front and its seasonal migration are highly variable among the IPCC models (Ninomiya 2009; Inoue and Ueda 2009), suggesting that distribution of low-level clouds over the KOE region may also be highly model dependent. Relatively high-resolution models are necessary to properly simulate air-sea interactions in the vicinity of the WBCs and their associated fronts (Maloney and Chelton 2006; Taguchi et al. 2009). Minobe et al. (2008) show that the impacts of an SST front can extend through the depth of the troposphere. This has implications for properly modeling eddy-mean flow interactions, as discussed in the following section. Current large-scale atmospheric models also have difficulty simulating the 

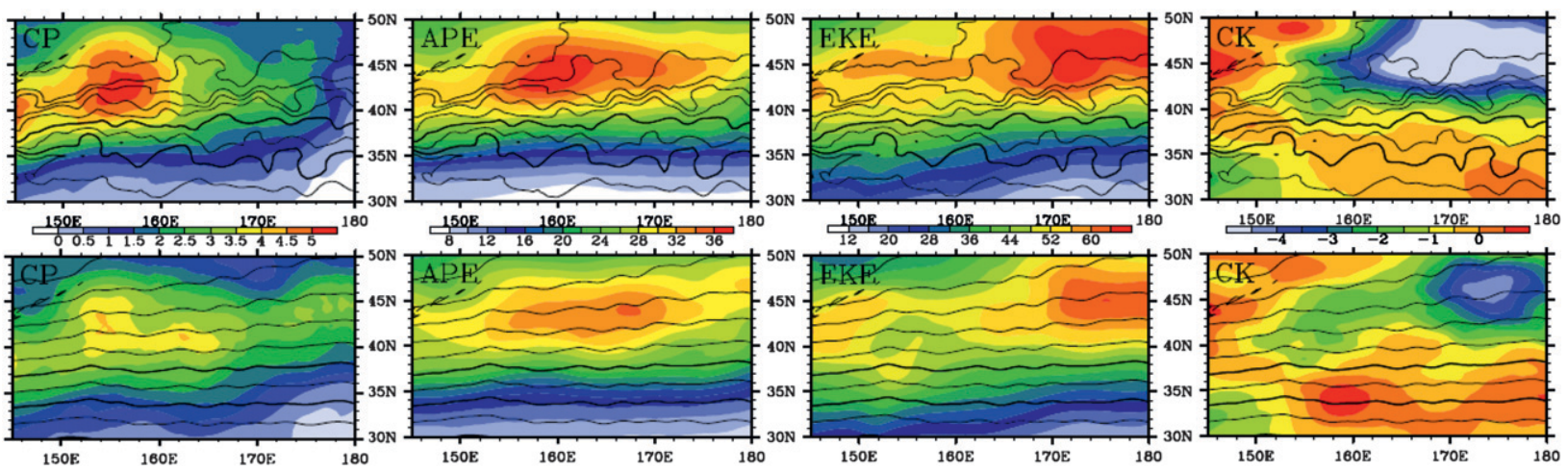

FIG. 16. (left to right) Vertically averaged distributions of available potential energy (APE) conversion $\left(10 \mathrm{~m}^{2} \mathrm{~s}^{-2}\right.$ day $\left.{ }^{-1}\right)$, eddy APE $\left(\mathrm{m}^{2} \mathrm{~s}^{-2}\right)$, eddy kinetic energy (KE) $\left(\mathrm{m}^{2} \mathrm{~s}^{-2}\right)$, and KE conversion $\left(10 \mathrm{~m}^{2} \mathrm{~s}^{-2} \mathrm{day}^{-1}\right)$ for spring 2004 with (top) observed frontal SST and (bottom) artificially smoothed SST as the boundary condition. The APE and KE conversions are defined to be positive where eddies extract energy from the seasonal mean flow. The SST is shown as a black line with 1 K CI (Taguchi et al. 2009).

atmospheric boundary layer, especially when it is stably stratified. Tokinaga et al. $(2006,2009)$ and Tanimoto et al. (2009) show how the changes in the sense of the stratification across a WBC can cause changes in the characteristics of boundary layer clouds. Prospects for improving processes associated with the climate feedbacks in climate models are discussed by Bony et al. (2006).

\section{Outstanding issues}

While substantial progress has been made in our understanding of WBC variability and its impact on climate variability, several outstanding issues remain.

\section{a. How are the frontal-scale and basin-scale atmosphere-ocean interactions related?}

The frontal zones associated with the WBCs cover a substantial fraction of the zonal width of the basins, along which decadal SST variability is particularly strong, and they control a large part of the heat and moisture release to the atmosphere (section 2). Evidence that the frontalscale features have a substantial impact on the basin-scale tropospheric climatology is given by Minobe et al. (2008) and Taguchi et al. (2009). The latter authors used a highresolution atmospheric model of the North Pacific to investigate the influence of the resolution of the SST used as the prescribed boundary condition. The impact of the frontal SST gradient in the KOE region on the storm track activity is illustrated in Fig. 16. With the frontal SST gradient, the eddy activity is substantially enhanced and the negative kinetic energy conversion is stronger, indicating stronger eddy forcing on the formation and maintenance of the eddy-driven polar-front jet.

As reviewed by Small et al. (2008) and Kelly et al. (2010), there is much evidence that the atmospheric boundary layer is locally affected by the SST variability near oceanic fronts, and Joyce et al. (2009) found that the large-scale shifts in the path of the GS and the KE were causing significant changes in the near-surface synoptic activity. However, it has not been confirmed using observations whether such changes in the PBL influence the free atmosphere aloft and the large-scale atmospheric circulation. Atmospheric models seem sensitive to rather large-scale SSTAs, but this may be dependent on the limited resolution of the models that have been used so far. Assessing the global influence of the sharp frontal zones and air-sea feedback will require high-resolution regional coupled models imbedded into global ones, or very high-resolution coupled models.

\section{b. What is the large-scale atmospheric circulation/ wind stress curl response to the WBC SSTAs?}

\section{1) Gulf Stream}

Because extratropical SSTAs are strongly influenced by the atmosphere, even in WBC regions, their feedback onto the atmospheric circulation must be detected by investigating covariability when SST leads the atmosphere by more than the atmospheric persistence and response time. Based on this method, Czaja and Frankignoul (1999, 2002) have shown that the observed North Atlantic horseshoe (NAH) SSTA pattern has a significant influence on the NAO in early winter. The NAH SSTA has a center of action in the GS-NAC region (Fig. 17). There are two other centers of action, but Wang et al. (2004; see also Ciasto and Thompson 2004) found that they had no significant link to later behavior of the NAO. As geostrophic advection influences SST and heat content in the GS-NAC region, changes in GS transport should influence the large-scale atmospheric circulation via the NAH SSTA. However, the latter seems to be largely forced by the atmosphere during summer 
(Czaja and Frankignoul 2002; Fletcher and Saunders 2006), and attempts have failed at relating the NAO to prior shifts in the GS path (Frankignoul et al. 2001).

On the other hand, some sensitivity studies with AGCMs suggest that it is the North Atlantic SSTA tripole and SST in the tropical Atlantic that influence the NAO, albeit mostly in late winter, while the direct influence of the NAH SSTA in early winter is small (e.g., Peng et al. 2002, 2005; Cassou et al. 2007). As the tripole is largely forced by the NAO, there could be a positive feedback between SST and the NAO, possibly through anomalous storm-track activity (Kushnir et al. 2002). The feedback could enhance the low-frequency variability of the latter, in particular in view of the strong reemergence of the tripole (section 2e). The NAH pattern projects onto the tripole, so that observations also suggest a weak positive SST-NAO feedback.

\section{2) Kuroshio}

It is difficult to identify the influence of North Pacific SSTAs on the atmospheric circulation using observations because of the confounding effects of the PNA-like remote response to ENSO. Nonetheless, SSTAs in the $\mathrm{KOE}$ region seem to have a statistically significant influence on the atmosphere during certain seasons (Liu et al. 2006; Frankignoul and Sennéchael 2007). After removing the ENSO signal, an equivalent barotropic atmospheric signal in late summer is significantly correlated with SSTAs in the previous spring with a strong center of action in the KOE region (Fig. 18). The summer anomaly pattern is most significant in the upper troposphere and has a ridge above the warm SST. The SST anomaly is largest in the KOE region and is surrounded by negative anomalies, resembling the first North Pacific SSTA EOF from winter to early summer. Its time series shows some resemblance to the winter SSTAs in the KE region (Qiu 2000), which were strongly influenced by anomalous geostrophic advection and direct atmospheric forcing. Similar but weaker atmospheric anomalies are also found when regressing on the northeastern SST center of action, but comparable ones are found when regressing on the southeastern SST center, which suggests that the basinwide SSTA pattern seems to influence the atmosphere. Qiu et al. (2007) found a relation between winter SST in the KE band and spring $\nabla \times \tau$. Although the latter signal is noisy, it has a zonal dipole structure that could lead to a weak delayed negative feedback on the KE variability.

Many early studies with AGCMs focused on the winter response to idealized North Pacific SSTAs. The results are diverse, with responses ranging between equivalent barotropic and baroclinic, presumably because of differences in background climatology and storm track
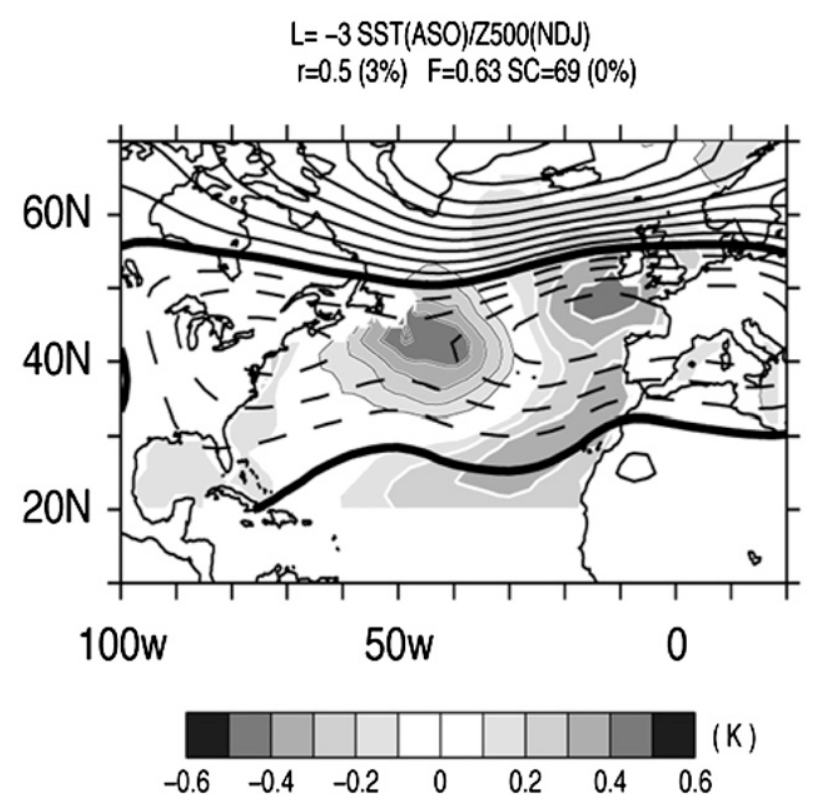

FIG. 17. Maximum covariance pattern between monthly geopotential height anomalies at $500 \mathrm{hPa}(\mathrm{CI}=5 \mathrm{~m}$, with negative values dashed) in early winter and previous SST anomalies (gray shading with white contours for positive values and black contours for positive values), based on the NCEP reanalysis in 1958-97. Here $L$ indicates the lag in month (months are given by their first letter), $C$ is correlation, $\mathrm{SC}$ is the square covariance, and $F$ is the $\mathrm{SC}$ fraction. Here, the 3-month lag does not indicate delayed response but reflects SST persistence and the finite atmospheric response time. Statistical significance is indicated. (From Czaja and Frankignoul 2002).

location (Kushnir et al. 2002). Recent studies have mostly focused on interpreting the decadal variability of climate models. For instance, Pierce et al. (2001) found a baroclinic warm-ridge (shifted northeastward) 500-hPa annual response to the dominant SSTA, with a positive $\nabla \times \tau$ over a warm anomaly in the KOE. Adding an initial upper-ocean temperature anomaly to a low-resolution coupled model, Liu et al. (2007) found that the atmospheric response varied with the season, with an equivalent barotropic warm-ridge response (also shifted northeastward) in early winter showing some similarity with the observations. In late winter, however, a very different pattern (mostly annular) was found. Kwon and Deser (2007) prescribed the geostrophic heat flux divergence that largely controlled the decadal SST changes in the KOE of a coupled model, using an ML model coupled to its atmospheric component. The $\nabla \times \tau$ response was mostly local, corresponding to a baroclinic warm-low response (Fig. 19). This is broadly of the opposite sign to the main $\nabla \times \boldsymbol{\tau}$ forcing, suggesting a weak delayed negative feedback. Note that the $\nabla \times \tau$ response has the opposite sign in the KOE than in Qiu et al. (2007). Hence, modeling studies suggest that an active coupling with the 

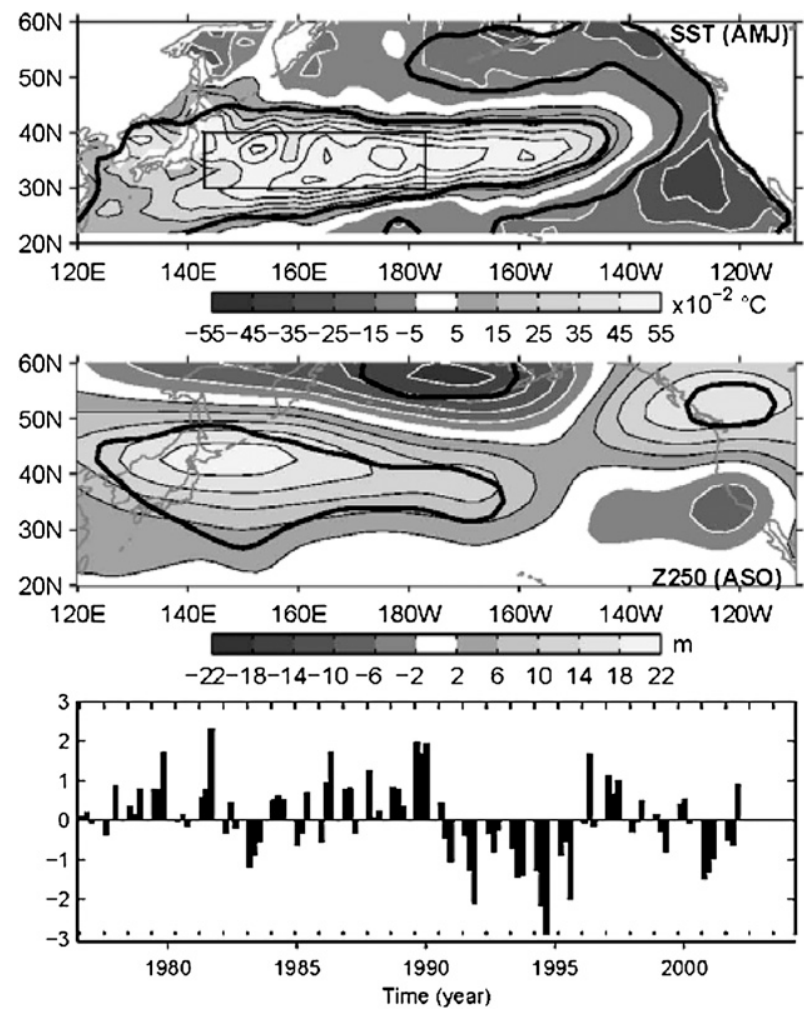

FIG. 18. (top) Regression of monthly anomalies of SST in AMJ and (middle) 250-hPa geopotential height 4 months later in ASO onto the AMJ SST anomalies in the KE box shown in the upper panel [(bottom) time series], based on the NCEP reanalysis in 1977-2004. The ENSO signal and a quadratic trend have been removed, and the thick line indicates the $5 \%$ level of significance. See Frankignoul and Sennéchael (2007) for details.

KOE may be at play, but the response to the decadal KOE variations seems model dependent.

\section{c. Global warming and the WBCs}

SSTs over the Northern Hemisphere WBCs have warmed over the last 25 years (Solomon et al. 2007; Guan and Nigam 2008). How the WBC will evolve in warming conditions is difficult to ascertain since most current climate models used in the IPCC global warming scenarios have too coarse a resolution to satisfactorily resolve the WBCs. High-resolution coupled models are being developed, however, and it will soon be possible to pursue the issue.

High-resolution simulations with the Model for Interdisciplinary Research on Climate 3.2 (MIROC3.2; T106 resolution in the atmosphere, eddy-permitting in the ocean) provide a first view on how the WBC might evolve in a warming world, based on a $1 \% \mathrm{yr}^{-1} \mathrm{CO}_{2}$ increase (Sakamoto et al. 2005). The model represents the Kuroshio path well in present-day conditions, but the GS is slightly too far north and is too zonal in the central North Atlantic
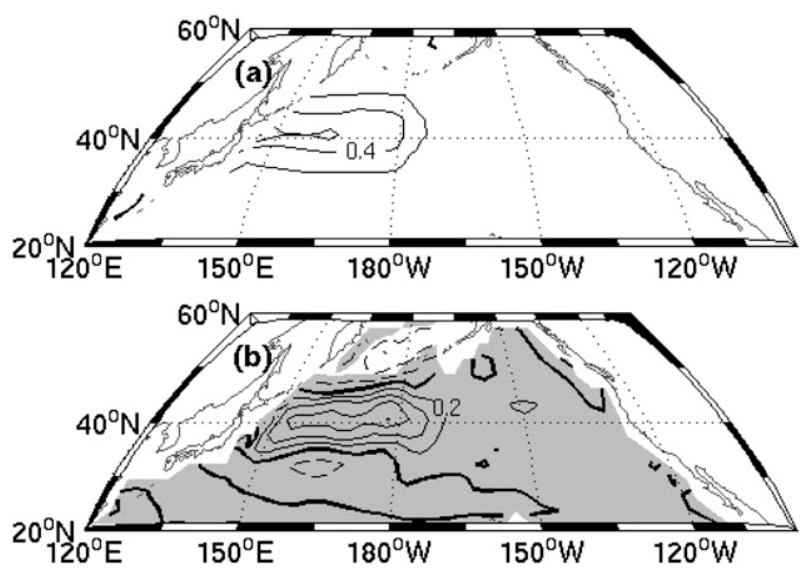

FIG. 19. Annual mean (a) SST and (b) wind stress curl response from the CAM2 ocean mixed layer model integration with specified heat flux divergence in the $\mathrm{KE}$. CI is $0.2^{\circ} \mathrm{C}$ for SST and $0.2 \times$ $10^{-8} \mathrm{~N} \mathrm{~m}^{-3}$ for wind stress curl. Negative values are dashed; shading indicates a response significant at the $1 \%$ level. (From Kwon and Deser 2007).

(Fig. 20). In warming conditions, the velocity in the KE and the OE increases, without significant changes in their axes. The KE intensification reflects the spinup of the southern recirculation gyre by North Pacific $\nabla \times \tau$ changes, which appear to be due to an El Niño-like warming in the tropics. In contrast, the GS and its front weaken, perhaps because of MOC influence, as discussed below.

On the other hand, in the "time slice experiments" of Sato et al. (2006), where an eddy-permitting model of the North Pacific basin was forced with the mean atmospheric condition for 2040-80 derived from the lowresolution Meteorological Research Institute Coupled GCM (MRI CGCM), the Kuroshio axis was displaced poleward by $3^{\circ}-4^{\circ}$ without much change in intensity, since the MRI CGCM response to global warming is characterized by an AO-like poleward shift of surface westerlies over the North Pacific. Although such a time slice experiment with a regional ocean model may be critically affected by atmospheric circulation biases due to the poor representation of the WBC in low-resolution coupled models, it stresses that the North Pacific atmospheric response to global warming may be model dependent and needs to be further investigated.

\section{d. Relation between the Gulf Stream and the MOC}

Given that the warm return branch of the Atlantic MOC (AMOC) contributes to the net GS transport, it is expected that the GS should intensify when the AMOC is stronger. However, it is the change in the GS position, not its strength, that has long been monitored, and its relation to AMOC remains controversial. Several mechanisms may control the meridional displacements of the GS 

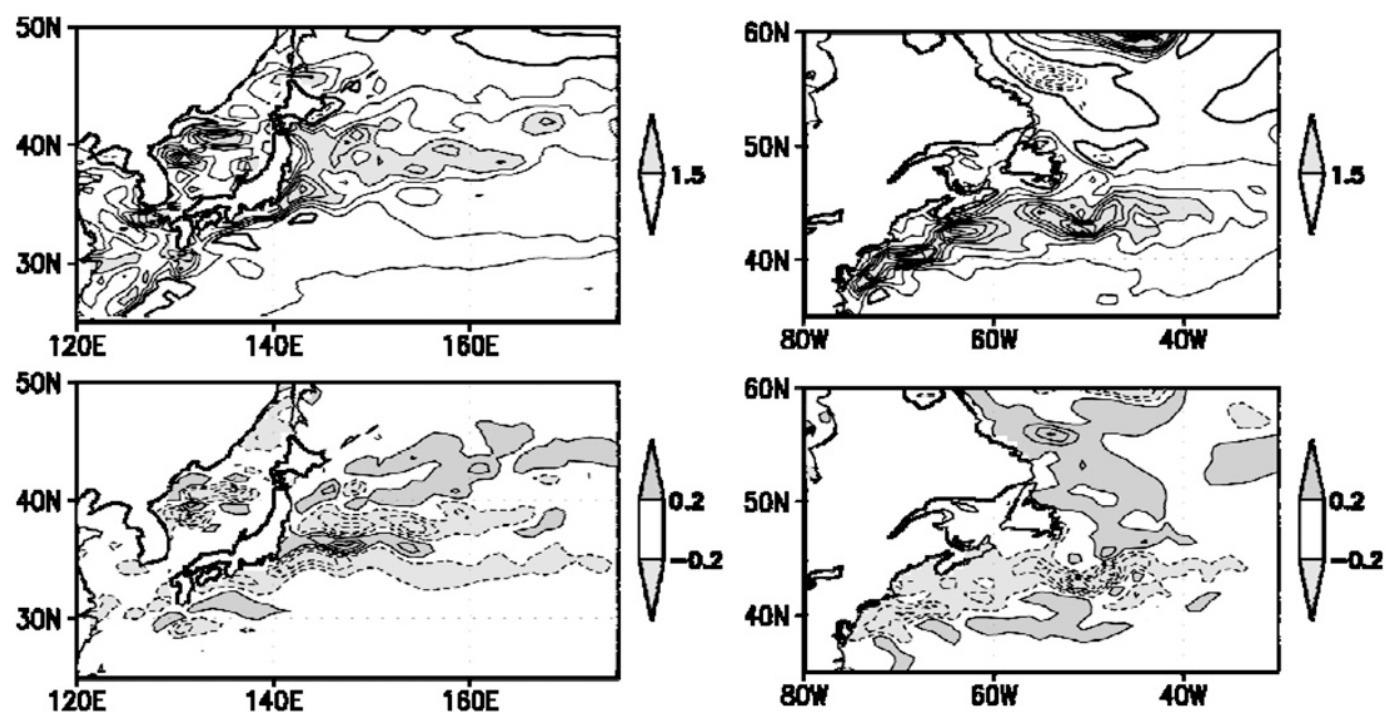

FIG. 20. (top) Long-term mean meridional temperature gradient in the control run (1971-2000) and (bottom) its difference between the end of the $\mathrm{CO}_{2}$ run (2071-2100) and the control runs for the (left) western North Pacific and (right) North Atlantic with MIROC3.2. Units are ${ }^{\circ} \mathrm{C}\left({ }^{\circ} \text { latitude }\right)^{-1}$. (From T. Miyasaka 2009, personal communication).

axis, its main mode of low-frequency variability, which tends to lag the NAO by about $1 \mathrm{yr}$ in the observations (Taylor and Stephens 1998; Joyce et al. 2000; Frankignoul et al. 2001). In the positive NAO phase, the westerlies intensify and their axis moves northward, resulting in an anticyclonic $\boldsymbol{\nabla} \times \boldsymbol{\tau}$ anomaly that should increase the GS transport and indeed shift it northward, after adjustment by baroclinic Rossby waves. The cooling of the subpolar gyre in a positive NAO phase also enhances deep convection and should intensify the AMOC, probably after a delay of 1 to 3 years (e.g., Eden and Willebrand 2001; Böning et al. 2006; Deshayes and Frankignoul 2008). Hence, AMOC and GS may vary in phase as they respond to NAO forcing coherently, as in the intermediateresolution model hindcasts examined by de Coëtlogon et al. (2006).

Another candidate for controlling the GS position is the bottom torque associated with the DWBC in the Slope Water region and at the GS-DWBC crossover. Thompson and Schmitz (1989), Gerdes and Köberle (1995), and Zhang and Vallis (2007), among others, have shown that a strong DWBC west of the Grand Banks increases the bottom vortex stretching, leading to a stronger northern recirculation gyre and a GS that is located farther south than with a weak DWBC. If bottom torque determines the GS position, then intensification of the AMOC and the DWBC (possibly linked to NAO forcing) should lead to a southward shift of the GS, opposite to the relation above. This was the case in Ezer (1999), but observed and simulated GS shifts showed little resemblance. The agreement was better in Zhang and Vallis (2006) where the GS shift was also out of phase with the AMOC, but this may be due to the strong freshwater forcing that was prescribed in a rather ad hoc manner. However, Peña-Molino and Joyce (2008) found that the essentially barotropic slope currents near $70^{\circ} \mathrm{W}$ lead the GS shifts by 6 months and suggested that an increased DWBC transport indeed precedes a southward GS shift. Nonlinearity, eddy dynamics, and other factors may also influence the GS position, such as the entrainment of the upper core of the DWBC (Spall 1996) and changes in the Labrador Sea shelf transport (Rossby and Benway 2000).

The relation between GS and AMOC is illustrated in Fig. 21 for an eddy-permitting hindcast (described in Tréguier et al. 2007), which simulates the GS rather realistically. The main mode of low-frequency variability of the GS position is a meridional displacement of its axis, as observed, while the main mode of gyre variability represents an in-phase modulation of the strength of the subpolar and subtropical gyres, and the main AMOC mode is primarily a modulation of the mean AMOC strength (Fig. 21). These three modes broadly evolve in phase, so that the GS is stronger and in a northerly position when the AMOC is intensified and the subpolar gyre stronger. The observed weakening of the subpolar gyre after the mid-1990s (Häkkinen and Rhines 2004, 2009) is well reproduced in Fig. 21, with the barotropic streamfunction EOF being consistent with the observed first SSH EOF. However, the southward GS shift since the mid-1990s is not seen in the observed GS path from Joyce et al. (2009) and Peña-Molino and Joyce (2008), 

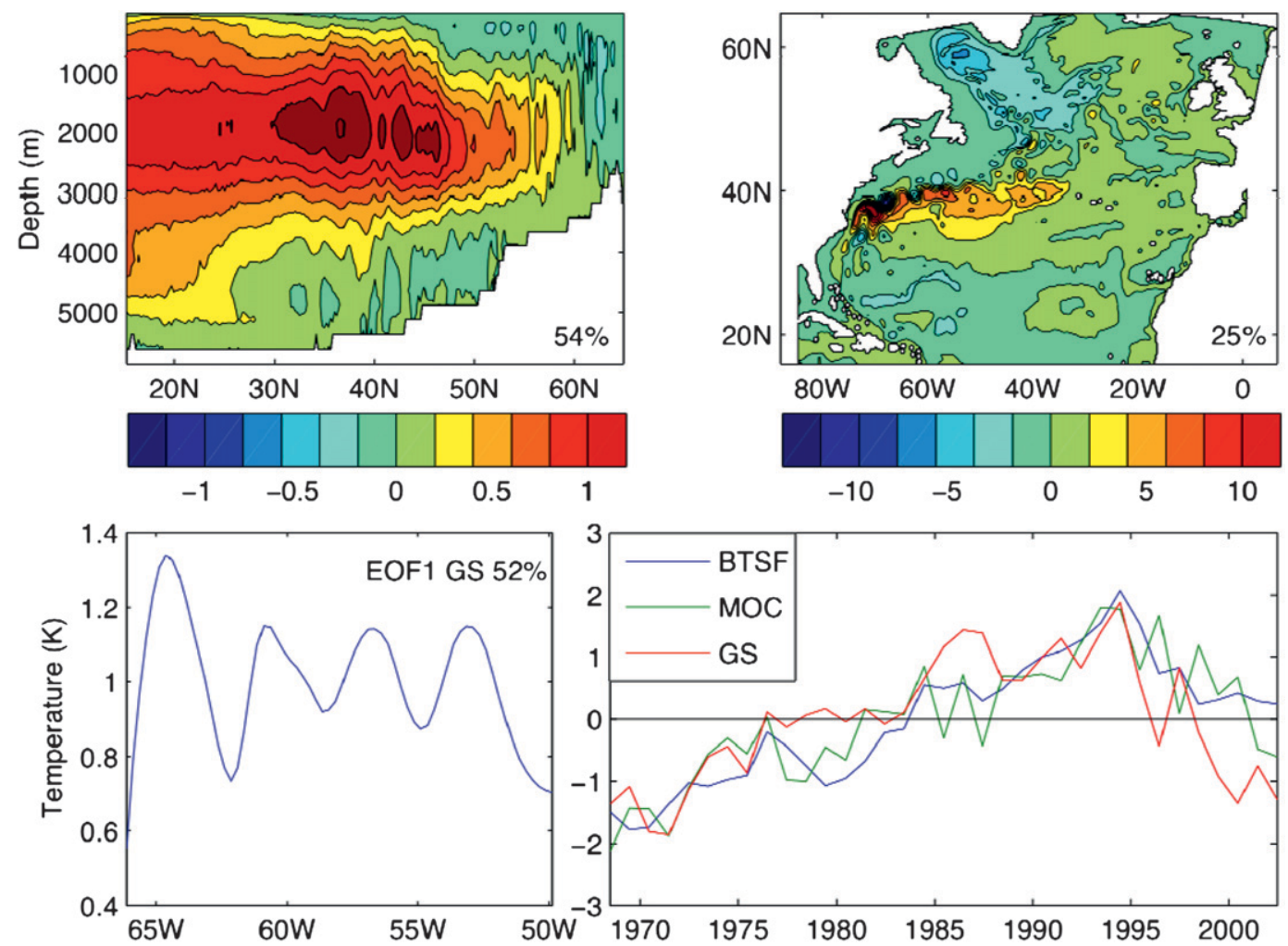

FIG. 21. First EOF of the (top left) AMOC $\left[\mathrm{Sv}\left(1 \mathrm{~Sv} \equiv 10^{6} \mathrm{~m}^{3} \mathrm{~s}^{-1}\right)\right]$, (top right) the barotropic streamfunction (BTSF; in Sv), and (bottom left) the GS shifts (as estimated by the temperature changes at 270-m depth along its mean axis) and (bottom right) the corresponding normalized principal components in a 1958-2002 hindcast with the global ORCA025 model forced by fields derived from ERA-40. The run started from Levitus climatology, and the first 10 years are omitted. A temperature increase along the GS axis corresponds to a northward shift.

perhaps because of dominance of interannual variability. Zhang (2008) has shown that the GS position and the subpolar gyre strength also vary in phase in the GFDL CM2.1 coupled model but that their relation with the AMOC is opposite (i.e., the GS shifts south when the AMOC intensifies). Since a southward shift of the GS would similarly be suggested by the observed subpolar gyre weakening, neither the hindcast nor the coupled model seems realistic enough to unambiguously establish which mechanisms primarily control the GS shifts and how they are related to the AMOC. Bryan et al. (2007) suggested that eddy-resolving models with a minimum resolution of $0.1^{\circ}$ and a sufficiently strong transport of overflow water are needed to get a realistic mean GS path. Further progress may thus require realistic hindcasts with eddy-resolving models.

\section{e. Connection between $G S$ and KOE variability}

The NAO is closely linked to the AO or Northern Hemisphere annular mode, which involves exchanges of mass between the polar region and the midlatitude, and modulation of the strength and position of the westerlies
(Thompson and Wallace 2000). The interbasin link between the North Atlantic and the North Pacific depends on season, however, as the AO most resembles the NAO in early winter, with a limited signal over the North Pacific, but is also influenced by the Aleutian-Icelandic low seesaw in late winter, which involves the PNA pattern and has a large amplitude over the North Pacific (Honda and Nakamura 2001; Honda et al. 2005, 2007). As the Icelandic low is at higher latitude than the Aleutian low, the seesaw changes the zonal wind and the surface turbulent heat flux over the North Atlantic and the North Pacific with a very similar latitudinal profile. Moreover, the latter closely resembles the profile associated with the NAO. The coordinated forcing of the two oceans, albeit stronger in late winter, should thus lead to coordinated changes in the two oceans. In the positive phase of the AO or the Aleutian-Icelandic low seesaw, the sensible heat flux into the ocean increases and evaporation and $\nabla \times \tau$ decrease in both the GS and KE regions, so that one expects the heat content to increase because of the surface warming and, after a delay, increased geostrophic advection of warm waters. Coordinated changes 


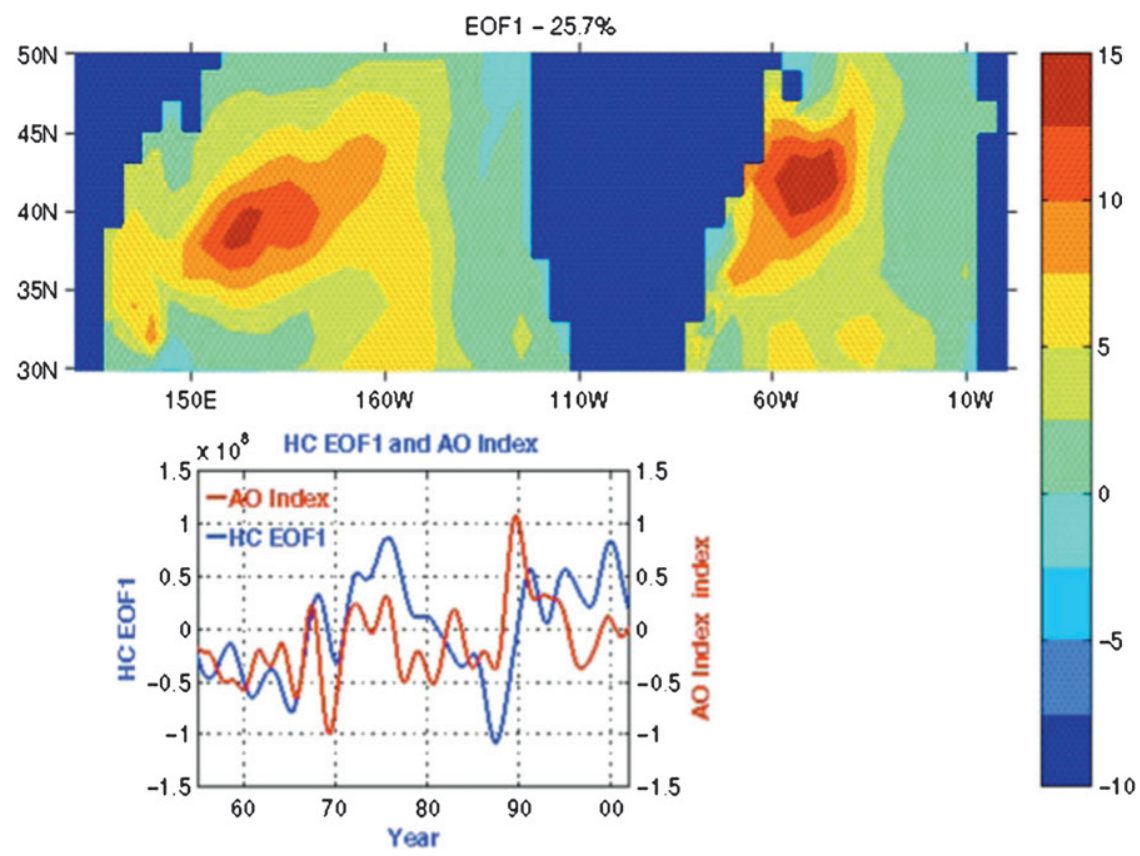

FIG. 22. (top) First EOF of 0-400-m heat content anomalies in the North Atlantic and North Pacific (from JEDAC) and (bottom) its time series. An index for the Arctic Oscillation is shown for comparison (correlation of 0.49 when the $\mathrm{AO}$ leads by 13 months). (From Kelly and Dong 2004).

in upper-ocean heat content in the $\mathrm{WBC}$ regions were found by Kelly and Dong (2004), lagging the AO by $1 \mathrm{yr}$ (Fig. 22). Since the changes in the two basins were considered simultaneously in an EOF analysis, it was not established whether the time lag was larger for the KE region, as expected from geostrophic adjustment in a larger basin, nor was it explained why it was so short. However, the upper-ocean heat content in the two broad regions in consideration is also driven by the local air-sea fluxes, so that the lag may reflect a mix of coordinated local and remote atmospheric forcing.

\section{Summary}

WBCs are unique locations in the midlatitude ocean. They are associated with a band of concentrated heat and moisture supply to the atmosphere with a sharp decline poleward across the associated oceanic frontal zones in the cold seasons. These fluxes influence the mean state of the atmosphere, for example, by allowing recurrent development of cyclones and thereby anchoring storm tracks. In summer, the frontal zones influence the mean distribution of low-level stratus. The WBCs are also unique in terms of being loci of low-frequency variability. SSTAs on time scales longer than a few years exhibit maximum variability around KOE and GS, primarily because of the reddening effect of Rossby wave adjustment of the ocean circulation in response to the basin-scale white noise-like $\nabla \times \tau$ forcing. The lowfrequency variability of GS is more complex than that in the KOE because of the interaction with the DWBCAMOC. Over most of the midlatitude ocean, $Q_{\text {net }}$ variability is primarily controlled by the atmospheric variability: $Q_{\text {net }}$ forcing on SSTAs dominates the negative $Q_{\text {net }}$ feedback that tends to damp them after they are generated. In the KOE and GS, however, low-frequency SSTAs are primarily driven by oceanic processes, manifested primarily as the meridional migration of major oceanic frontal zones with tight SST gradient, while the turbulent heat fluxes primarily damp SSTAs, thereby heating the overlying atmosphere. Therefore, WBCs are of potential importance to decadal climate variability, depending on how and to what extent the atmospheric circulation responds to the anomalous heat and moisture provided from the underlying ocean. Some climate model studies indicate that the basin-scale atmospheric circulation response is strong enough and of the correct spatial structure to generate decadal variability, even though current-generation climate models exhibit substantial deficiencies in reproducing WBCs, which can result in incorrect climate responses. However, the observational evidence is yet very limited and the AGCM response to SSTAs or surface flux anomalies in the WBCs varies greatly among models. Recent observations show that 
the ocean-atmosphere interaction plays a significant role in the mean climate and variability of the WBC marine boundary layer (see Kelly et al. 2010). Nevertheless, the implication of these relatively small-scale, near-surface changes for the basin-scale climate variability is presently unclear. Assessing basin/global-scale influence of the frontal-scale air-sea feedback will require high-resolution regional coupled models embedded into global ones, or very high-resolution global coupled models. While experiments with increased model resolution clearly improve the simulation of frontal-scale features, advances in model physics including the representation of atmosphere and ocean boundary layers; the heat, freshwater, and momentum fluxes at their interface; marine stratiform clouds; boundary current strength and separation; interaction between eddies; and the ocean mixed layer are also needed to address the full spectrum of air-sea interaction over WBCs and climate variability.

Acknowledgments. The authors of this paper are members of the working group on Western Boundary Current Air-Sea Interaction sponsored by U.S. CLIVAR (http://www.usclivar.org/Organization/wbc-wg.html). We appreciate the support from the U.S. CLIVAR office. We also thank Jamie Scott, Takafumi Miyasaka, and Barb DeLuisi for developing the WBC web page and for producing some of the figures and two anonymous reviewers for their constructive suggestions. Funding for LT was provided by the NASA-sponsored Ocean Surface Topography Science Team, under Contract 1267196 with the University of Washington, administered by the Jet Propulsion Laboratory. HN was supported in part by the Grant-in-Aid 18204044 by the Japan Society for Promotion for Science (JSPS) and the Global Environment Research Fund (S-5) of the Japanese Ministry of Environment. YK was supported by the Kerr Endowed Fund and Penzance Endowed Fund.

\section{REFERENCES}

Alexander, M. A., 1990: Simulation of the response of the North Pacific Ocean to the anomalous atmospheric circulation associated with El Niño. Climate Dyn., 5, 53-65.

_ 1992: Midlatitude atmosphere-ocean interaction during El Niño. Part I: The North Pacific Ocean. J. Climate, 5, 944-958.

_ , and C. Deser, 1995: A mechanism for the recurrence of wintertime midlatitude SST anomalies. J. Phys. Oceanogr., 25, 122-137.

- and J. D. Scott, 2008: The role of Ekman ocean heat transport in the Northern Hemisphere response to ENSO. J. Climate, 21, 5688-5707.

_, C. Deser, and M. S. Timlin, 1999: The reemergence of SST anomalies in the North Pacific Ocean. J. Climate, 12, 2419-2433.

— M. S. Timlin, and J. D. Scott, 2001: Winter-to-winter recurrence of sea surface temperature, salinity, and mixed layer depth anomalies. Prog. Oceanogr., 49, 41-61.
I. Bladé, M. Newman, J. R. Lanzante, N.-C. Lau, and J. D. Scott, 2002: The atmospheric bridge: The influence of ENSO teleconnections on air-sea interaction over the global oceans. J. Climate, 15, 2205-2231.

, N.-C. Lau, and J. D. Scott, 2004: Broadening the atmospheric bridge paradigm: ENSO teleconnections to the North Pacific in summer and to the tropical west Pacific-Indian Oceans over the seasonal cycle. Earth's Climate: The Ocean-Atmosphere Interaction, Geophys. Monogr., Vol. 147, Amer. Geophys. Union, 85-104.

, and Coauthors, 2006: Extratropical atmosphere-ocean variability in CCSM3. J. Climate, 19, 2496-2525.

, L. Matrosova, C. Penland, J. D. Scott, and P. Chang, 2008: Forecasting Pacific SSTs: Linear inverse model predictions of the PDO. J. Climate, 21, 385-402.

Álvarez-García, F., M. Latif, and A. Biastoch, 2008: On multidecadal and quasi-decadal North Atlantic variability. J. Climate, 21, 3433-3452.

Annamalai, H., H. Okajima, and M. Watanabe, 2007: Possible impact of the Indian Ocean SST on the Northern Hemisphere circulation during El Niño. J. Climate, 20, 3164-3189.

Bader, D. C., C. Covey, W. J. Gutowski Jr., I. M. Held, K. E. Kunkel, R. L. Miller, R. T. Tokmakian, and M. H. Zhang, 2008: Climate models: An assessment of strengths and limitations. U.S. Climate Change Science Program and the Subcommittee on Global Change Research, Office of Biological and Environmental Research, Department of Energy, 124 pp. [Available online at http://www.climatescience.gov/Library/sap/sap3-1/ final-report/sap3-1-final-all.pdf.]

Bader, J., and M. Latif, 2003: The impact of decadal-scale Indian Ocean sea surface temperature anomalies on Sahelian rainfall and the North Atlantic Oscillation. Geophys. Res. Lett., 30, 2169, doi:10.1029/2003GL018426.

Barlow, M., S. Nigam, and E. H. Berbery, 2001: ENSO, Pacific decadal variability, and U.S. summertime precipitation, drought, and stream flow. J. Climate, 14, 2105-2128.

Belkin, I., R. Krishfield, and S. Honjo, 2002: Decadal variability of the North Pacific polar front: Subsurface warming versus surface cooling. Geophys. Res. Lett., 29, 1351, doi:10.1029/2001GL013806.

Bellucci, A., S. Gualdi, E. Scoccimarro, and A. Navarra, 2008: NAOocean circulation interactions in a coupled general circulation model. Climate Dyn., 31, 759-777.

Bengtsson, L., K. I. Hodges, and E. Roeckner, 2006: Storm tracks and climate change. J. Climate, 19, 3518-3543.

Berloff, P., A. M. Hogg, and W. Dewar, 2007: The turbulent oscillator: A mechanism of low-frequency variability of the wind-driven ocean gyres. J. Phys. Oceanogr., 37, 2363-2386.

Bhatt, U. S., M. A. Alexander, D. S. Battisti, D. D. Houghton, and L. M. Keller, 1998: Atmosphere-ocean interaction in the North Atlantic: Near-surface climate variability. J. Climate, 11, 1615-1632.

Bjerknes, J., 1969: Atlantic air-sea interaction. Advances in Geophysics, Vol. 10, Academic Press, 1-82.

Bond, N. A., and M. F. Cronin, 2008: Regional weather patterns during anomalous air-sea fluxes at the Kuroshio Extension Observatory (KEO). J. Climate, 21, 1680-1697.

Böning, C. W., M. Scheinert, J. Dengg, A. Biastoch, and A. Funk, 2006: Decadal variability of subpolar gyre transport and its reverberation in the North Atlantic overturning. Geophys. Res. Lett., 33, L21S01, doi:10.1029/2006GL026906.

Bony, S., and Coauthors, 2006: How well do we understand and evaluate climate change feedback processes? J. Climate, 19, $3445-3482$. 
Bryan, F. O., M. W. Hecht, and R. D. Smith, 2007: Resolution convergence and sensitivity studies with North Atlantic circulation models. Part I: The western boundary current system. Ocean Modell., 16, 141-159.

Carton, J. A., and B. S. Giese, 2008: A reanalysis of ocean climate using Simple Ocean Data Assimilation (SODA). Mon. Wea. Rev., 136, 2999-3017.

Cassou, C., and L. Terray, 2001: Oceanic forcing of the wintertime low frequency atmospheric variability in the North Atlantic European sector: A study with the ARPEGE model. J. Climate, 14, 4266-4291.

— C. Deser, L. Terray, J. W. Hurrell, and M. Drévillon, 2004: Summer sea surface temperature conditions in the North Atlantic and their impact upon the atmospheric circulation in early winter. J. Climate, 17, 3349-3363.

,-- , and M. A. Alexander, 2007: Investigating the impact of reemerging sea surface temperature anomalies on the winter atmospheric circulation over the North Atlantic. J. Climate, 20, 3510-3526.

Cayan, D. R., 1992: Latent and sensible heat flux anomalies over the northern oceans: Driving the sea surface temperature. J. Phys. Oceanogr., 22, 859-881.

Ceballos, L. I., E. Di Lorenzo, C. D. Hoyos, N. Schneider, and B. Taguchi, 2009: North Pacific Gyre Oscillation synchronizes climate fluctuations in the eastern and western boundary systems. J. Climate, 22, 5163-5174.

Chang, E. K. M., S. Lee, and K. L. Swanson, 2002: Storm track dynamics. J. Climate, 15, 2163-2183.

Chelton, D. B., and M. G. Schlax, 1996: Global observations of oceanic Rossby waves. Science, 272, 234-238.

Ciasto, L. M., and D. W. J. Thompson, 2004: North Atlantic atmosphere-ocean interaction on intraseasonal time scales. J. Climate, 17, 1617-1621.

Colin de Verdière, A., and T. Huck, 1999: Baroclinic instability: An oceanic wavemaker for interdecadal variability. J. Phys. Oceanogr., 29, 893-910.

Collins, M., S. F. B. Tett, and C. Cooper, 2001: The internal climate variability of HadCM3, a version of the Hadley Centre coupled model without flux adjustments. Climate Dyn., 17, 61-81.

Czaja, A., and C. Frankignoul, 1999: Influence of the North Atlantic SST on the atmospheric circulation. Geophys. Res. Lett., 26, 2969-2972.

— and - 2002: Observed impact of Atlantic SST anomalies on the North Atlantic oscillation. J. Climate, 15, 606-623.

Dawe, J. T., and L. Thompson, 2005: Viscosity-dependent internal variability in a model of the North Pacific. J. Phys. Oceanogr., 35, 747-756.

— changes in a model of the North Pacific. J. Climate, 20, 20922108.

de Coëtlogon, G., and C. Frankignoul, 2003: The persistence of winter sea surface temperature in the North Atlantic. J. Climate, 16, 1364-1377.

,-- M. Bentsen, C. Delon, H. Haak, S. Masina, and A. Pardaens, 2006: Gulf Stream variability in five oceanic general circulation models. J. Phys. Oceanogr., 36, 2119 2135.

Delworth, T., S. Manabe, and R. Stouffer, 1993: Interdecadal variations of the thermohaline circulation in a coupled oceanatmosphere model. J. Climate, 6, 1993-2011.

, and Coauthors, 2006: GFDL's CM2 global coupled climate models. Part I: Formulation and simulation characteristics. J. Climate, 19, 643-674.
Deser, C., and M. L. Blackmon, 1993: Surface climate variations over the North Atlantic Ocean during winter: 1900-1989. J. Climate, 6, 1743-1753.

— , and - 1995: On the relationship between tropical and North Pacific sea surface temperature variations. J. Climate, $\mathbf{8}$, 1677-1680.

—, M. A. Alexander, and M. S. Timlin, 1999: Evidence for a wind-driven intensification of the Kuroshio Current Extension from the 1970s to the 1980s. J. Climate, 12, 1697-1706.

_ A. A. Phillips, and J. W. Hurrell, 2004: Pacific interdecadal climate variability: Linkages between the tropics and the North Pacific during boreal winter since 1900. J. Climate, 17, 3109-3124.

Deshayes, J., and C. Frankignoul, 2008: Simulated variability of the circulation in the North Atlantic from 1953 to 2003. J. Climate, 21, 4919-4933.

Dewar, W. K., 2001: On ocean dynamics in midlatitude climate. J. Climate, 14, 4380-4397.

Dong, B., and R. T. Sutton, 2005: Mechanism of interdecadal thermohaline circulation variability in a coupled ocean-atmosphere GCM. J. Climate, 18, 1117-1135.

Dong, S., and K. A. Kelly, 2003: The seasonal and interannual variations in the geostrophic currents in the Middle Atlantic bight. J. Geophys. Res., 108, 3172, doi:10.1029/2002JC001357.

— and _ 2004: Heat budget in the Gulf Stream region: The importance of heat storage and advection. J. Phys. Oceanogr., 34, 1214-1231.

Drévillon, M., C. Cassou, and L. Terray, 2003: Model study of the North Atlantic region atmospheric response to autumn tropical Atlantic sea-surface-temperature anomalies. Quart. J. Roy. Meteor. Soc., 129, 2591-2611.

Eden, C., and J. Willebrand, 2001: Mechanism of interannual to decadal variability of the North Atlantic circulation. J. Climate, 14, 2266-2280

Enfield, D. B., A. M. Mestas-Nuñez, and P. J. Trimble, 2001: The Atlantic Multidecadal Oscillation and its relationship to rainfall and river flows in the continental U.S. Geophys. Res. Lett., 28 , 2077-2080.

Ezer, T., 1999: Decadal variabilities of the upper layers of the subtropical North Atlantic: An ocean model study. J. Phys. Oceanogr., 29, 3111-3124.

Ferreira, D., C. Frankignoul, and J. Marshall, 2001: Coupled ocean-atmosphere dynamics in a simple midlatitude climate model. J. Climate, 14, 3704-3723.

Fletcher, C. G., and M. A. Saunders, 2006: Winter North Atlantic Oscillation hindcast skill: 1900-2001. J. Climate, 19, 57625776.

Frankignoul, C., and E. Kestenare, 2002: The surface heat flux feedback. Part I: Estimates from observations in the Atlantic and the North Pacific. Climate Dyn., 19, 633-647.

— and - 2005: Observed Atlantic SST anomaly impact on the NAO: An update. J. Climate, 18, 4089-4094.

— and N. Sennéchael, 2007: Observed influence of North Pacific SST anomalies on the atmospheric circulation. J. Climate, 20, 592-606.

_ , P. Müller, and E. Zorita, 1997: A simple model of the decadal response of the ocean to stochastic wind forcing. J. Phys. Oceanogr., 27, 1533-1546.

—, G. de Coëtlogon, T. M. Joyce, and S. Dong, 2001: Gulf Stream variability and ocean-atmosphere interactions. J. Phys. Oceanogr., 31, 3516-3529.

Geng, Q., and M. Sugi, 2003: Possible change of extratropical cyclone activity due to enhanced greenhouse gases and sulfate 
aerosols-Study with a high-resolution AGCM. J. Climate, 16, 2262-2274.

Gerdes, R., and C. Köberle, 1995: On the influence of DSOW in a numerical model of the North Atlantic general circulation. J. Phys. Oceanogr., 25, 2624-2642.

Gnanadesikan, A., and Coauthors, 2006: GFDL's CM2 global coupled climate models. Part II: The baseline ocean simulation. J. Climate, 19, 675-697.

Grötzner, A., M. Latif, and T. P. Barnett, 1998: A decadal climate cycle in the North Atlantic Ocean as simulated by the ECHO coupled GCM. J. Climate, 11, 831-847.

Guan, B., and S. Nigam, 2008: Pacific sea surface temperatures in the twentieth century: An evolution-centric analysis of variability and trend. J. Climate, 21, 2790-2809.

Haarsma, R. J., and W. Hazeleger, 2007: Extratropical atmospheric response to equatorial Atlantic cold tongue anomalies. J. Climate, 20, 2076-2091.

Häkkinen, S., and P. B. Rhines, 2004: Decline of subpolar North Atlantic circulation during the 1990s. Science, 304, $555-559$.

— and - 2009: Shifting surface currents in the northern North Atlantic Ocean. J. Geophys. Res., 114, C04005, doi:10.1029/ 2008JC004883.

Hanawa, K., and S. Sugimoto, 2004: "Reemergence" areas of winter sea surface temperature anomalies in the world's oceans. Geophys. Res. Lett., 31, L10303, doi:10.1029/2004GL019904.

— - Y. Yoshikawa, and T. Watanabe, 1989: Composite analyses of wintertime wind stress vector fields with respect to SST anomalies in the western North Pacific and the ENSO events. Part II: ENSO composite. J. Meteor. Soc. Japan, 67, 833-844.

Hoerling, M. P., J. Hurrell, and T. Xu, 2001: Tropical origins for recent North Atlantic climate change. Science, 292, 90-92.

— J. W. Hurrell, T. Xu, G. T. Bates, and A. S. Phillips, 2004: Twentieth century North Atlantic climate change. Part II: Understanding the effect of Indian Ocean warming. Climate Dyn., 23, 391-405.

Honda, M., and H. Nakamura, 2001: Interannual seesaw between the Aleutian and Icelandic lows. Part II: Its significance in the interannual variability over the wintertime Northern Hemisphere. J. Climate, 14, 4512-4529.

_- S. Yamane, and H. Nakamura, 2005: Impacts of the AleutianIcelandic low seesaw on surface climate during the twentieth century. J. Climate, 18, 2793-2802.

$\_, \ldots$, and $—$, 2007: Inter-basin link between the North Pacific and North Atlantic in the upper tropospheric circulation: Its dominance and seasonal dependence. J. Meteor. Soc. Japan, 85, 898-908.

Hoskins, B. J., and P. J. Valdes, 1990: On the existence of storm tracks. J. Atmos. Sci., 47, 1854-1864.

Huck, T., and G. K. Vallis, 2001: Linear stability analysis of the three-dimensional thermally-driven ocean circulation: Application to interdecadal variability. Tellus, 53A, 526-545.

$\longrightarrow,-\ldots$, and A. Colin de Verdière, 2001: On the robustness of the interdecadal modes of the thermohaline circulation. J. Climate, 14, 940-963.

Inoue, T., and H. Ueda, 2009: Evaluation for the seasonal evolution of the summer monsoon over the Asian-western Pacific sector in the WCRP CMIP3 multi-model experiments. J. Meteor. Soc. Japan, 87, 539-560.

Jin, F.-F., 1997: A theory of interdecadal climate variability of the North Pacific ocean-atmosphere system. J. Climate, 10, 18211835.
Joyce, T. M., C. Deser, and M. A. Spall, 2000: The relation between decadal variability of subtropical mode water and the North Atlantic Oscillation. J. Climate, 13, 2550-2569.

— , Y.-O. Kwon, and L. Yu, 2009: On the relationship between synoptic wintertime atmospheric variability and path shifts in the Gulf Stream and the Kuroshio Extension. J. Climate, 22, 3177-3192.

Kelly, K. A., and S. Dong, 2004: The relationship of western boundary current heat transport and storage to mid-latitude ocean-atmosphere interaction. Earth's Climate: The OceanAtmosphere Interaction, Geophys. Monogr., Vol. 147, Amer. Geophys. Union, 347-363.

— L. Thompson, W. Cheng, and E. J. Metzger, 2007: Evaluation of HYCOM in the Kuroshio Extension region using new metrics. J. Geophys. Res., 112, C01004, doi:10.1029/2006JC003614.

— , R. J. Small, R. M. Samelson, B. Qiu, T. M. Joyce, Y.-O. Kwon, and M. Cronin, 2010: Western Boundary Currents and frontal air-sea interaction: Gulf Stream and Kuroshio Extension. J. Climate, in press.

Kistler, R., and Coauthors, 2001: The NCEP-NCAR 50-Year Reanalysis: Monthly Means CD-ROM and documentation. Bull. Amer. Meteor. Soc., 82, 247-267.

Klein, S. A., D. L. Hartmann, and J. R. Norris, 1995: On the relationships among low-cloud structure, sea surface temperature and atmospheric circulation in the summertime northeast Pacific. J. Climate, 8, 1140-1155.

Kravtsov, S., W. K. Dewar, P. Berloff, J. C. McWilliams, and M. Ghil, 2007: A highly nonlinear coupled mode of decadal variability in a mid-latitude ocean-atmosphere model. Dyn. Atmos. Oceans, 43, 123-150.

Kubota, M., N. Iwasaka, S. Kizu, M. Konda, and K. Kutsuwada, 2002: Japanese ocean flux data sets with use of remote sensing observations (J-OFURO). J. Oceanogr., 58, 213-225.

Kushnir, Y., 1994: Interdecadal variations in North Atlantic sea surface temperature and associated atmospheric conditions. J. Climate, 7, 141-157.

—, W. A. Robinson, I. Bladé, N. M. J. Hall, S. Peng, and R. Sutton, 2002: Atmospheric GCM response to extratropical SST anomalies: Synthesis and evaluation. J. Climate, 15, 22332256.

Kwon, Y.-O., and C. Deser, 2007: North Pacific decadal variability in the Community Climate System model version 2. J. Climate, 20, 2416-2433.

Ladd, C., and L. Thompson, 2001: Water mass formation in an isopycnal model of the North Pacific. J. Phys. Oceanogr., 31, $1517-1537$.

Large, W. G., and G. Danabasoglu, 2006: Attribution and impacts of upper-ocean biases in CCSM3. J. Climate, 19, 2325-2346.

Latif, M., and T. P. Barnett, 1994: Causes of decadal climate variability over the North Pacific and North America. Science, 266, 634-637.

— , and — 1996: Decadal climate variability over the North Pacific and North America: Dynamics and predictability. J. Climate, 9, 2407-2423.

Lau, N.-C., and M. J. Nath, 1994: A modeling study of the relative roles of tropical and extratropical SST anomalies in the variability of the global atmosphere-ocean system. J. Climate, 7, 1184-1207.

— linking tropical Pacific ENSO events to extratropical SST anomalies. J. Climate, 9, 2036-2057.

- and - 2001: Impact of ENSO on SST variability in the North Pacific and North Atlantic: Seasonal dependence and 
role of extratropical sea-air coupling. J. Climate, 14, 28462866.

Lewis, J. M., D. Koracin, and K. Redmond, 2004: Sea fog research in the United Kingdom and United States: A historical essay including outlook. Bull. Amer. Meteor. Soc., 85, 395-408.

Linkin, M. E., and S. Nigam, 2008: The North Pacific OscillationWest Pacific teleconnection pattern: Mature-phase structure and winter impacts. J. Climate, 21, 1979-1997.

Liu, Q., N. Wen, and Z. Liu, 2006: An observational study of the impact of the North Pacific SST on the atmosphere. Geophys. Res. Lett., 33, L18611, doi:10.1029/2006GL026082.

Liu, Z., 1999a: Forced planetary wave response in a thermocline gyre. J. Phys. Oceanogr., 29, 1036-1055.

_ 1999b: Planetary wave modes in thermocline circulation: Non-Doppler-shift mode, advective mode and Green mode. Quart. J. Roy. Meteor. Soc., 125, 1315-1339.

— and M. Alexander, 2007: Atmospheric bridge, oceanic tunnel and global climatic teleconnections. Rev. Geophys., 45, RG2005, doi:10.1029/2005RG000172.

— , Y. Liu, L. Wu, and R. Jacob, 2007: Seasonal and long-term atmospheric responses to reemerging North Pacific Ocean variability: A combined dynamical and statistical assessment. J. Climate, 20, 955-980.

Maloney, E. D., and D. B. Chelton, 2006: An assessment of the sea surface temperature influence on surface wind stress in numerical weather prediction and climate models. J. Climate, 19, 2743-2762.

Maltrud, M. E., and J. L. McClean, 2005: An eddy resolving global $1 / 10^{\circ}$ ocean simulation. Ocean Modell., 8, 31-54.

Mantua, N. J., S. R. Hare, Y. Zhang, J. M. Wallace, and R. Francis, 1997: A Pacific interdecadal climate oscillation with impacts on salmon production. Bull. Amer. Meteor. Soc., 78, 10691079.

Marshall, J., H. Johnson, and J. Goodman, 2001: A study of the interaction of the North Atlantic Oscillation with ocean circulation. J. Climate, 14, 1399-1421.

Masumoto, Y., and Coauthors, 2004: A fifty-year eddy-resolving simulation of the World Ocean-Preliminary outcomes of OFES (OGCM for the Earth Simulator). J. Earth Simul., 1, $35-56$.

Mathieu, P.-P., R. T. Sutton, B. Dong, and M. Collins, 2004: Predictability of winter climate over the North Atlantic European region during ENSO events. J. Climate, 17, 1953-1974.

Miller, A. J., D. R. Cayan, and W. B. White, 1998: A westwardintensified decadal change in the North Pacific thermocline and gyre-scale circulation. J. Climate, 11, 3112-3127.

Miller, R. L., G. A. Schmidt, and D. T. Shindell, 2006: Forced annular variations in the 20th century Intergovernmental Panel on Climate Change Fourth Assessment Report models. J. Geophys. Res., 111, D18101, doi:10.1029/2005JD006323.

Minobe, S., 1997: A 50-70-year climatic oscillation over the North Pacific and North America. Geophys. Res. Lett., 24, 683-686.

—- A. Kuwano-Yoshida, N. Komori, S. Xie, and R. J. Small, 2008: Influence of the Gulf Stream on the troposphere. Nature, 452, 206-209.

Molinari, R. L., Z. Garraffo, and D. Snowden, 2008: Differences between observed and a coupled simulation of North Atlantic sea surface currents and temperature. J. Geophys. Res., 113, C09011, doi:10.1029/2008JC004848.

Nakamura, H., and T. Yamagata, 1999: Recent decadal SST variability in the northwestern Pacific and associated atmospheric anomalies. Beyond El Niño: Decadal and Interdecadal Climate Variability, A. Navarra, Ed., Springer, 49-72.
— and A. S. Kazmin, 2003: Decadal changes in the North Pacific oceanic frontal zones as revealed in ship and satellite observations. J. Geophys. Res., 108, 3078, doi:10.1029/1999JC000085.

_ G. Gin, and T. Yamagata, 1997: Decadal climate variability in the North Pacific during the recent decades. Bull. Amer. Meteor. Soc., 78, 2215-2225.

— T. Sampe, Y. Tanimoto, and A. Shimpo, 2004: Observed associations among storm tracks, jet streams and midlatitude oceanic fronts. Earth's Climate: The Ocean-Atmosphere Interaction, Geophys. Monogr., Vol. 147, Amer. Geophys. Union, 329-346.

,,-- A. Goto, W. Ohfuchi, and S.-P. Xie, 2008: On the importance of midlatitude oceanic frontal zones for the mean state and dominant variability in the tropospheric circulation. Geophys. Res. Lett., 35, L15709, doi:10.1029/2008GL034010.

Namias, J., and R. M. Born, 1970: Temporal coherence in North Pacific sea-surface temperature patterns. J. Geophys. Res., 75, 5952-5955.

— North Pacific sea surface temperatures. J. Geophys. Res., 79, 797-798.

Neelin, J. D., and W. Weng, 1999: Analytical prototypes for ocean-atmosphere interaction at midlatitudes. Part I: Coupled feedbacks as a sea surface temperature dependent stochastic process. J. Climate, 12, 697-721.

Newman, M., 2007: Interannual to decadal predictability of tropical and North Pacific sea surface temperatures. J. Climate, 20, 2333-2356.

, G. P. Compo, and M. A. Alexander, 2003: ENSO-forced variability of the Pacific decadal oscillation. J. Climate, 16, 3853-3857.

Ninomiya, K., 2006: Features of the polar air outbreak and the energy balance in the transformed air-mass observed over the Japan Sea. J. Meteor. Soc. Japan, 84, 529-542.

_ 2009: Characteristics of precipitation in the Meiyu-Baiu season in the CMIP3 20th century climate simulations. J. Meteor. Soc. Japan, 87, 829-843.

Nishii, K., T. Miyasaka, Y. Kosaka, and H. Nakamura, 2009: Reproducibility and future projection of the midwinter stormtrack activity over the Far East in the CMIP3 climate models in relation to "Haru-Ichiban" over Japan. J. Meteor. Soc. Japan, 87, 581-588.

Nitta, T., and S. Yamada, 1989: Recent warming of tropical sea surface temperature and its relationship to the Northern Hemisphere circulation. J. Meteor. Soc. Japan, 67, 375-383.

Nonaka, M., H. Nakamura, Y. Tanimoto, T. Kagimoto, and H. Sasaki, 2006: Decadal variability in the Kuroshio-Oyashio Extension simulated in an eddy-resolving OGCM. J. Climate, 19, 19701989.

$-,-\longrightarrow,-$, and,- 2008: Interannual-to-decadal variability in the Oyashio and its influence on temperature in the subarctic frontal zone: An eddy-resolving OGCM simulation. J. Climate, 21, 6283-6303.

—_ - B. Taguchi, N. Komori, A. Kuwano-Yoshida, and K. Takaya, 2009: Air-sea heat exchanges characteristic of a prominent midlatitude oceanic front in the South Indian Ocean as simulated in a high-resolution coupled GCM. J. Climate, 22, $6515-6535$.

Norris, J. R., and C. B. Leovy, 1994: Interannual variability in stratiform cloudiness and sea surface temperature. J. Climate, 7, 1915-1925.

, and S. R. Iacobellis, 2005: North Pacific cloud feedbacks inferred from synoptic-scale dynamic and thermodynamic relationships. J. Climate, 18, 4862-4878. 
_ - Y. Zhang, and J. M. Wallace, 1998: Role of clouds on summertime atmosphere-ocean interactions over the North Pacific. J. Climate, 11, 2482-2490.

Ohfuchi, W., H. Sasaki, Y. Masumoto, and H. Nakamura, 2007: "Virtual" atmospheric and oceanic circulations in the Earth Simulator. Bull. Amer. Meteor. Soc., 88, 861-866.

Oshima, K., and Y. Tanimoto, 2009: An evaluation of reproducibility of Pacific Decadal Oscillation in the CMIP3 simulations. J. Meteor. Soc. Japan, 87, 755-770.

Osychny, V., and P. Cornillon, 2004: Properties of Rossby waves in the North Atlantic estimated from satellite data. J. Phys. Oceanogr., 34, 61-76.

Park, S., and C. B. Leovy, 2004: Marine low-cloud anomalies associated with ENSO. J. Climate, 17, 3448-3469.

- C. Deser, and M. A. Alexander, 2005: Estimation of the surface heat flux response to sea surface temperature anomalies over the global oceans. J. Climate, 18, 4582-4599.

_ - M. A. Alexander, and C. Deser, 2006: The impact of cloud radiative feedback, remote ENSO forcing, and entrainment on the persistence of North Pacific sea surface temperature anomalies. J. Climate, 19, 6243-6261.

Peña-Molino, B., and T. M. Joyce, 2008: Variability in the Slope Water and its relation to the Gulf Stream path. Geophys. Res. Lett., 35, L03606, doi:10.1029/2007GL032183.

Peng, S., and J. S. Whitaker, 1999: Mechanisms determining the atmospheric response to midlatitude SST anomalies. J. Climate, 12, 1393-1408.

_ W. A. Robinson, and S. Li, 2002: North Atlantic SST forcing of the NAO and relationships with intrinsic hemispheric variability. Geophys. Res. Lett., 29, 1276, doi:10.1029/2001GL014043.

,,,--- and M. P. Hoerling, 2005: Tropical Atlantic SST forcing of coupled North Atlantic seasonal responses. J. Climate, 18, 480-496.

,,--- , and M. A. Alexander, 2006: Effects of Ekman transport on the NAO response to a tropical Atlantic SST anomaly. J. Climate, 19, 4803-4818.

Pierce, D. W., T. P. Barnett, N. Schneider, R. Saravanan, D. Dommenget, and M. Latif, 2001: The role of ocean dynamics in producing decadal climate variability in the North Pacific. Climate Dyn., 18, 51-70.

Pozo-Vázquez, D., M. J. Esteban-Parra, F. S. Rodrigo, and Y. Castro-Díez, 2001: The association between ENSO and winter atmospheric circulation and temperature in the North Atlantic region. J. Climate, 14, 3408-3420.

Qiu, B., 2000: Interannual variability of the Kuroshio Extension system and its impact on the wintertime SST field. J. Phys. Oceanogr., 30, 1486-1502.

_ 2003: Kuroshio Extension variability and forcing of the Pacific decadal oscillations: Responses and potential feedback. J. Phys. Oceanogr., 33, 2465-2482.

— , and K. A. Kelly, 1993: Upper-ocean heat balance in the Kuroshio Extension region. J. Phys. Oceanogr., 23, 2027-2041.

- , and S. Chen, 2005: Variability of the Kuroshio Extension jet, recirculation gyre, and mesoscale eddies on decadal time scales. J. Phys. Oceanogr., 35, 2090-2103.

_ - N. Schneider, and S. Chen, 2007: Coupled decadal variability in the North Pacific: An observationally constrained idealized model. J. Climate, 20, 3602-3620.

Reynolds, R. W., T. M. Smith, C. Liu, D. B. Chelton, K. S. Casey, and M. G. Schlax, 2007: Daily high-resolution-blended analyses for sea surface temperature. J. Climate, 20, 5473-5496.

Ringer, M. A., and Coauthors, 2006: The physical properties of the atmosphere in the New Hadley Centre Global Environmenta
Model (HadGEM1). Part II: Aspects of variability and regional climate. J. Climate, 19, 1302-1326.

Rodwell, M. J., M. Drévillon, C. Frankignoul, J. W. Hurrell, H. Pohlmann, M. Stendel, and R. T. Sutton, 2004: North Atlantic forcing of climate and its uncertainty from a multi-model experiment. Quart. J. Roy. Meteor. Soc., 130, 2013-2032.

Rossby, T., and R. L. Benway, 2000: Slow variations in mean path of the Gulf Stream east of Cape Hatteras. Geophys. Res. Lett., 27, 117-120.

Saji, N. H., and T. Yamagata, 2003: Possible impacts of Indian Ocean dipole mode events on global climate. Climate Res., 25, 151-169.

Sakamoto, T. T., H. Hasumi, M. Ishii, S. Emori, T. Suzuki, T. Nishimura, and A. Sumi, 2005: Responses of the Kuroshio, and the Kuroshio Extension to global warming in a highresolution climate model. Geophys. Res. Lett., 32, L14617, doi:10.1029/2005GL023384.

Sampe, T., H. Nakamura, A. Goto, and W. Ohfuchi, 2010: Significance of a midlatitude SST frontal zone in the formation of a storm track and an eddy-driven westerly jet. J. Climate, 23, 1793-1814.

Saravanan, R., and J. C. McWilliams, 1997: Stochasticity and spatial resonance in interdecadal climate fluctuations. J. Climate, 10, 2299-2320.

Sato, Y., S. Yukimoto, H. Tsujino, H. Ishizaki, and A. Noda, 2006: Response of North Pacific Ocean circulation in a Kuroshioresolving ocean model to an Arctic Oscillation (AO)-like change in Northern Hemisphere atmospheric circulation due to greenhouse-gas forcing. J. Meteor. Soc. Japan, 84, 295-309.

Schneider, N., and A. J. Miller, 2001: Predicting western North Pacific Ocean climate. J. Climate, 14, 3997-4002. , and B. D. Cornuelle, 2005: The forcing of the Pacific decadal oscillation. J. Climate, 18, 4355-4373.

, A. J. Miller, and D. W. Pierce, 2002: Anatomy of North Pacific decadal variability. J. Climate, 15, 586-605.

Seager, R., Y. Kushnir, N. H. Naik, M. A. Cane, and J. Miller, 2001: Wind-driven shifts in the latitude of the Kuroshio-Oyashio Extension and generation of SST anomalies on decadal timescales. J. Climate, 14, 4249-4265.

Shaffrey, L., and R. Sutton, 2004: The interannual variability of energy transports within and over the Atlantic Ocean in a coupled climate model. J. Climate, 17, 1433-1448.

Sirven, J., C. Frankignoul, G. de Coëtlogon, and V. Taillandier, 2002: Spectrum of wind-driven baroclinic fluctuations of the ocean in the midlatitudes. J. Phys. Oceanogr., 32, 2405-2417.

Small, R. J., and Coauthors, 2008: Air-sea interaction over ocean fronts and eddies. Dyn. Atmos. Oceans, 45, 274-319.

Smith, R. D., M. E. Maltrud, F. O. Bryan, and M. W. Hecht, 2000: Numerical simulation of the North Atlantic Ocean at $1 / 10^{\circ}$. J. Phys. Oceanogr., 30, 1532-1561.

Solomon, S., D. Qin, M. Manning, M. Marquis, K. Averyt, M. M. B. Tignor, H. L. Miller Jr., and Z. Chen, Eds., 2007: Climate Change 2007: The Physical Science Basis. Cambridge University Press, 996 pp.

Spall, M. A., 1996: Dynamics of the Gulf Stream/deep western boundary current crossover. Part II: Low-frequency internal oscillations. J. Phys. Oceanogr., 26, 2169-2182.

Sturges, W., B. G. Hong, and A. J. Clarke, 1998: Decadal wind forcing of the North Atlantic subtropical gyre. J. Phys. Oceanogr., 28, 659-668.

Sugimoto, S., and K. Hanawa, 2005: Remote reemergence areas of winter sea surface temperature anomalies in the North Pacific. Geophys. Res. Lett., 32, L01606, doi:10.1029/2004GL021410. 
, and - , 2007: Impact of remote reemergence of the subtropical mode water on winter SST variation in the central North Pacific. J. Climate, 20, 173-186.

$\longrightarrow$, and - 2009: Decadal and interdecadal variations of the Aleutian low activity and their relation to upper oceanic variations over the North Pacific. J. Meteor. Soc. Japan, 87, 601-614.

Sutton, R. T., W. A. Norton, and S. P. Jewson, 2001: The North Atlantic Oscillation-What role for the ocean? Atmos. Sci. Lett., 1, 89-100.

Taguchi, B., S.-P. Xie, H. Mitsudera, and A. Kubokawa, 2005: Response of the Kuroshio Extension to Rossby waves associated with the 1970s climate regime shift in a high-resolution ocean model. J. Climate, 18, 2979-2995.

,-- , N. Schneider, M. Nonaka, H. Sasaki, and Y. Sasai, 2007: Decadal variability of the Kuroshio Extension: Observations and an eddy-resolving model hindcast. J. Climate, 20, 2357-2377.

— , H. Nakamura, M. Nonaka, and S.-P. Xie, 2009: Influence of the Kuroshio/Oyashio Extensions on air-sea heat exchanges and storm-track activity as revealed in regional atmospheric model simulations for the 2003/04 cold season. J. Climate, 22, 6536-6560.

Tanimoto, Y., H. Nakamura, T. Kagimoto, and S. Yamane, 2003: An active role of extratropical sea surface temperature anomalies in determining anomalous turbulent heat fluxes. J. Geophys. Res., 108, 3304, doi:10.1029/2002JC001750.

_- S.-P. Xie, K. Kai, H. Okajima, H. Tokinaga, T. Murayama, M. Nonaka, and H. Nakamura, 2009: Observations of marine atmospheric boundary layer transitions across the summer Kuroshio Extension. J. Climate, 22, 1360-1374.

Taylor, A. H., and J. A. Stephens, 1998: The North Atlantic Oscillation and the latitude of the Gulf Stream. Tellus, 50A, 134-142.

Taylor, G. I., 1917: The formation of fog and mist. Quart. J. Roy. Meteor. Soc., 43, 241-268.

Terray, L., and C. Cassou, 2002: Tropical Atlantic sea surface temperature forcing of quasi-decadal climate variability over the North Atlantic-European region. J. Climate, 15, 3170-3187.

Thomas, L. N., and C. M. Lee, 2005: Intensification of ocean fronts by down-front winds. J. Phys. Oceanogr., 35, 1086-1102.

Thompson, D. W. J., and J. M. Wallace, 2000: Annular modes in the extratropical circulation. Part I: Month-to-month variability. J. Climate, 13, 1000-1016.

Thompson, J. D., and W. J. Schmitz, 1989: A limited-area model of the Gulf Stream: Design, initial experiments and model-data intercomparison. J. Phys. Oceanogr., 19, 791-814.

Thompson, L., and C. Ladd, 2004: The response of the North Pacific Ocean to decadal variability in atmospheric forcing: Wind versus buoyancy forcing. J. Phys. Oceanogr., 34, 1373-1386.

—, and W. Cheng, 2008: Water masses in the Pacific in CCSM3. J. Climate, 21, 4514-4528.

Timlin, M. S., M. A. Alexander, and C. Deser, 2002: On the reemergence of North Atlantic SST anomalies. J. Climate, 15, 2707-2712.

Timmermann, A., M. Latif, R. Voss, and A. Grötzner, 1998: Northern Hemispheric interdecadal variability: A coupled air-sea mode. J. Climate, 11, 1906-1931.

Tokinaga, H., and Coauthors, 2006: Atmospheric sounding over the winter Kuroshio Extension: Effect of surface stability on atmospheric boundary layer structure. Geophys. Res. Lett., 33, L04703, doi:10.1029/2005GL025102.

, Y. Tanimoto, S.-P. Xie, T. Sampe, H. Tomita, and H. Ichikawa, 2009: Ocean frontal effects on the vertical development of clouds over the western North Pacific: In situ and satellite observations. J. Climate, 22, 4241-4260.
Tomita, T., S.-P. Xie, and M. Nonaka, 2002: Estimates of surface and subsurface forcing for decadal sea surface temperature variability in the mid-latitude North Pacific. J. Meteor. Soc. Japan, 80, 1289-1300.

Tréguier, A. M., M. H. England, S. R. Rintoul, G. Madec, J. Le Sommer, and J. M. Molines, 2007: Southern Ocean overturning across streamlines in an eddying simulation of the Antarctic Circumpolar current. Ocean Sci., 3, 491-507.

Trenberth, K. E., G. W. Branstator, D. Karoly, A. Kumar, N.-C. Lau, and C. Ropelewski, 1998: Progress during TOGA in understanding and modeling global teleconnections associated with tropical sea surface temperatures. J. Geophys. Res., 103 (C7), 14 291-14 324.

van Loon, H., and J. C. Rogers, 1978: The seesaw in winter temperatures between Greenland and Northern Europe. Part I: General description. Mon. Wea. Rev., 106, 296-310.

— , and R. A. Madden, 1981: The Southern Oscillation. Part I: Global associations with pressure and temperature in northern winter. Mon. Wea. Rev., 109, 1150-1162.

Vimont, D. J., 2005: The contribution of the interannual ENSO cycle to the spatial pattern of decadal ENSO-like variability. J. Climate, 18, 2080-2092.

Vivier, F., K. A. Kelly, and L. Thompson, 2002: Heat budget in the Kuroshio Extension region: 1993-99. J. Phys. Oceanogr., 32, 3436-3454.

Wallace, J. M., and D. S. Gutzler, 1981: Teleconnections in the geopotential height field during the Northern Hemisphere winter. Mon. Wea. Rev., 109, 784-812.

— , and P. V. Hobbs, 2006: Atmospheric Science: An Introductory Survey. 2nd ed. Academic Press, 483 pp.

Wang, W., B. T. Anderson, R. K. Kaufmann, and R. B. Myneni, 2004: The relation between the North Atlantic Oscillation and SSTs in the North Atlantic basin. J. Climate, 17, 4752-4759.

Watanabe, M., and M. Kimoto, 2000: On the persistence of decadal SST anomalies in the North Atlantic. J. Climate, 13, 3017-3028.

Weare, B., 1994: Interrelationships between cloud properties and sea surface temperatures on seasonal and interannual time scales. J. Climate, 7, 248-260.

White, W. B., 1995: Design of a global observing system for gyrescale upper ocean temperature variability. Prog. Oceanogr., 36, 169-217.

Wu, L., and Z. Liu, 2005: North Atlantic decadal variability: Airsea coupling, oceanic memory, and potential Northern Hemisphere resonance. J. Climate, 18, 331-349.

_ - D. E. Lee, and Z. Liu, 2005: The 1976/77 North Pacific climate regime shift: The role of subtropical ocean adjustment and coupled ocean-atmosphere feedbacks. J. Climate, 18, 5125-5140.

Xie, S.-P., T. Kunitani, A. Kubokawa, M. Nonaka, and S. Hosoda, 2000: Interdecadal thermocline variability in the North Pacific for 1958-97: A GCM simulation. J. Phys. Oceanogr., 30, 27982813.

_, K. Hu, J. Hafner, H. Tokinaga, Y. Du, G. Huang, and T. Sampe, 2009: Indian Ocean capacitor effect on IndoWestern Pacific climate during the summer following El Niño. J. Climate, 22, 730-747.

Xue, H., J. M. Bane Jr., and L. M. Goodman, 1995: Modification of the Gulf Stream through strong air-sea interactions in winter: Observations and numerical simulations. J. Phys. Oceanogr., 25, 533-557.

Yang, J. L., Q. Y. Liu, Z. Liu, L. Wu, and F. Huang, 2009: Basin mode of Indian Ocean sea surface temperature and Northern 
Hemisphere circumglobal teleconnection. Geophys. Res. Lett., 36, L19705, doi:10.1029/2009GL039559.

Yasuda, I., 2003: Hydrographic structure and variability in the Kuroshio-Oyashio transition area. J. Oceanogr., 59, 389-402.

_, K. Okuda, and Y. Shimizu, 1996: Distribution and modification of North Pacific Intermediate Water in the KuroshioOyashio interfrontal zone. J. Phys. Oceanogr., 26, 448-465.

Yeager, S. G., and M. Jochum, 2009: The connection between Labrador Sea buoyancy loss, Deep Western Boundary Current strength, and Gulf Stream path in an ocean circulation model. Ocean Modell., 30, 207-224.

Yu, L., X. Jin, and R. A. Weller, 2008: Multidecadel global flux datasets from the Objectively Analyzed Air-Sea Fluxes (OAFlux) Project: Latent and sensible heat fluxes, ocean evaporation, and related surface meteorological variables. Woods Hole Oceanographic Institution, OAFlux Project Tech. Rep. OA-2008-01, 64 pp. [Available online at http://oaflux.whoi.edu/.]

Yuan, X., and L. D. Talley, 1996: The subarctic frontal zone in the North Pacific: Characteristics of frontal structure from climatological data and synoptic surveys. J. Geophys. Res., 101, $16491-16508$
Zhang, R., 2008: Coherent surface-subsurface fingerprint of the Atlantic meridional overturning circulation. Geophys. Res. Lett., 35, L20705, doi:10.1029/2008GL035463.

_ , and G. K. Vallis, 2006: Impact of great salinity anomalies on the low-frequency variability of the North Atlantic climate. J. Climate, 19, 470-482.

_ and - 2007: The role of bottom vortex stretching on the path of the North Atlantic western boundary current and on the northern recirculation gyre. J. Phys. Oceanogr., 37, 2053-2080.

Zhang, Y., J. M. Wallace, and D. S. Battisti, 1997: ENSO-like interdecadal variability: 1900-93. J. Climate, 10, 1004-1020.

Zhong, Y., and Z. Liu, 2009: On the mechanism of Pacific multidecadal climate variability in CCSM3: The role of subpolar North Pacific Ocean. J. Phys. Oceanogr., 39, 2052-2076.

, - —, and R. Jacob, 2008: Origin of Pacific multidecadal variability in the Community Climate System Model, Version 3 (CCSM3): A combined statistical and dynamical assessment. J. Climate, 21, 114-133.

Zorita, E., and C. Frankignoul, 1997: Modes of North Atlantic decadal variability in the ECHAM1/LSG coupled oceanatmosphere general circulation model. J. Climate, 10, 183-200. 